\title{
DIFFERENTIATION AND INTIMATE PARTNER VIOLENCE
}

\author{
by \\ ADRIATIK LIKCANI \\ B.A., University of Tirana, Albania, 1995 \\ M.S., University of Nebraska-Lincoln, 2004 \\ M.S.W., University of Missouri-Kansas City, 2011
}

\author{
AN ABSTRACT OF A DISSERTATION \\ submitted in partial fulfillment of the requirements for the degree \\ DOCTOR OF PHILOSOHY \\ School of Family Studies and Human Services \\ College of Human Ecology \\ KANSAS STATE UNIVERSITY \\ Manhattan, Kansas
}

2013 


\begin{abstract}
This study explored the impact of differentiation of self on Intimate Partner Violence (IPV). First, the study determined if differentiation of self in a relationship added to the variance accounted for by the known risk factors including relational satisfaction, marital conflict, romantic jealousy, depression, anxiety, and attitude about violence towards women. Second, it examined the moderating effect of gender on the relationship between differentiation of self and IPV. Results indicated that differentiation of self in a relationship is a predictor of perpetration of intimate partner violence in relationships even after controlling for other known risk factors. Results also indicated that gender did not moderate the relationship between differentiation of self and perpetration of violence.
\end{abstract}




\title{
DIFFERENTIATION AND INTIMATE PARTNER VIOLENCE
}

by

\author{
ADRIATIK LIKCANI \\ B.A., University of Tirana, Albania, 1995 \\ M.S., University of Nebraska-Lincoln, 2004 \\ M.S.W., University of Missouri-Kansas City, 2011
}

\begin{abstract}
A DISSERTATION
submitted in partial fulfillment of the requirements for the degree DOCTOR OF PHILOSOHY

School of Family Studies and Human Services

College of Human Ecology

KANSAS STATE UNIVERSITY

Manhattan, Kansas
\end{abstract}

2013

Approved By:

Co-Major Professor

Sandra Stith, Ph.D.

Approved By:

Co-Major Professor

Farrell Webb, Ph.D. 


\section{Copyright}

ADRIATIK LIKCANI

2013 


\begin{abstract}
This study explored the impact of differentiation of self on Intimate Partner Violence (IPV). First, the study determined if differentiation of self in a relationship added to the variance accounted for by the known risk factors including relational satisfaction, marital conflict, romantic jealousy, depression, anxiety, and attitude about violence towards women. Second, it examined the moderating effect of gender on the relationship between differentiation of self and IPV. Results indicated that differentiation of self in a relationship is a predictor of perpetration of intimate partner violence in relationships even after controlling for other known risk factors. Results also indicated that gender did not moderate the relationship between differentiation of self and perpetration of violence.
\end{abstract}




\section{Table of Contents}

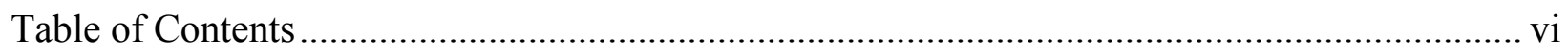

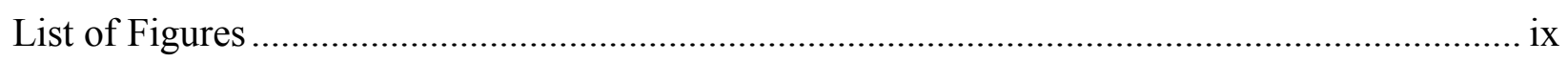

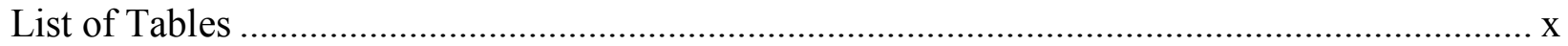

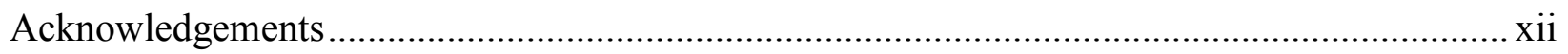

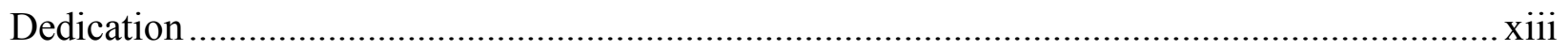

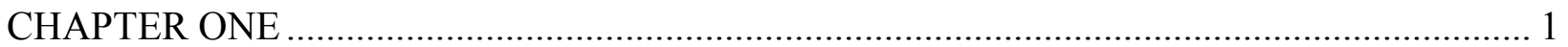

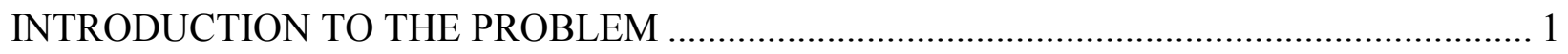

Differentiation and Intimate Partner Violence.................................................................... 1

Risk Factors for Intimate Partner Violence …………….................................................... 2

Differentiation and Intimate Partner Violence................................................................... 3

Purpose

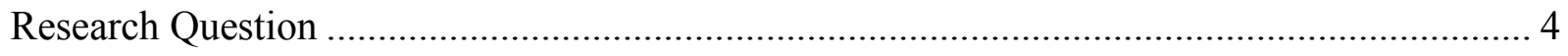

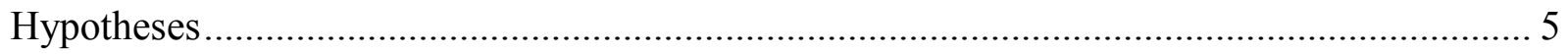

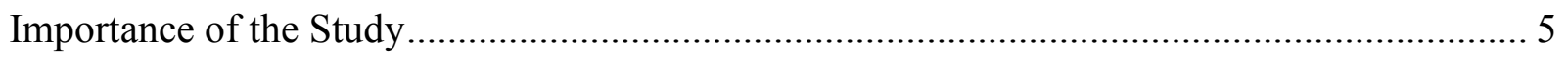

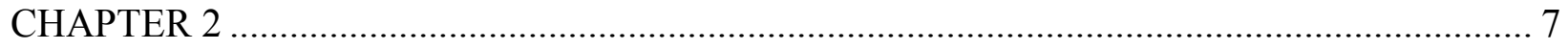

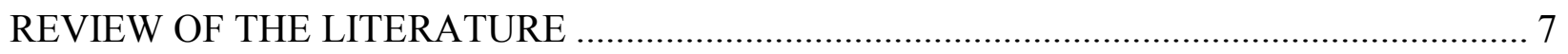

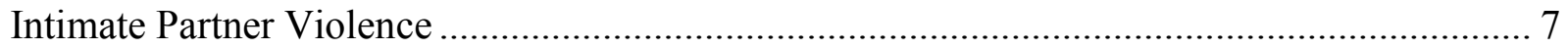

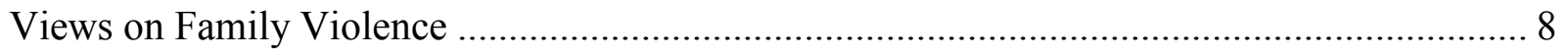

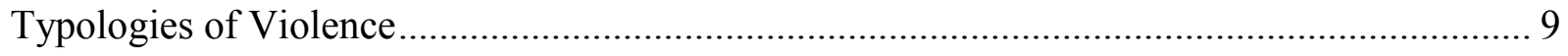

Theoretical Orientation: Bowen Family Systems Theory ……………………………......... 10

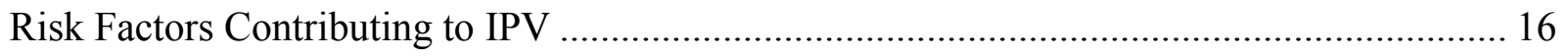

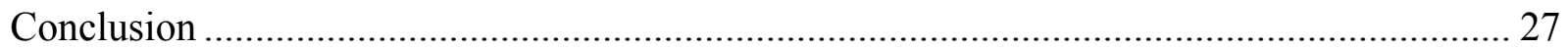




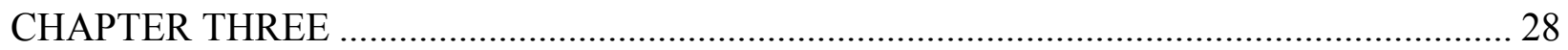

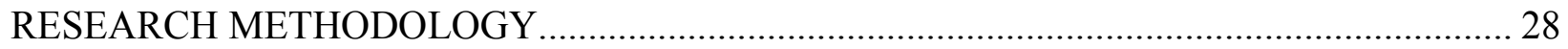

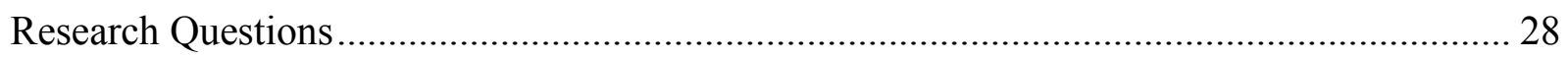

Research Hypotheses …………………….................................................................... 29

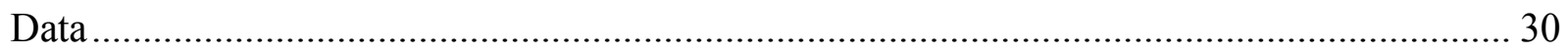

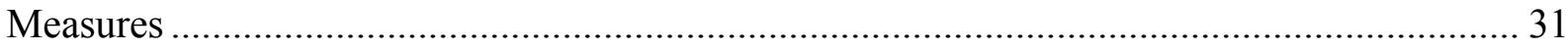

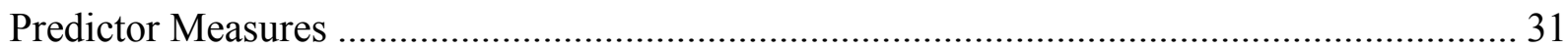

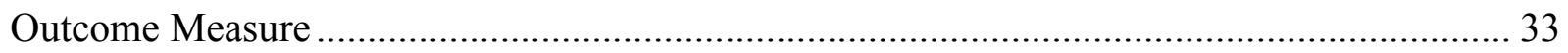

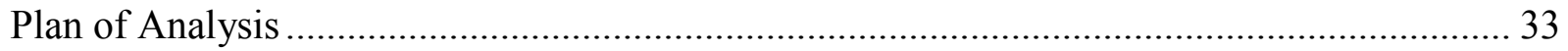

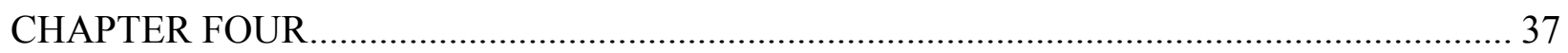

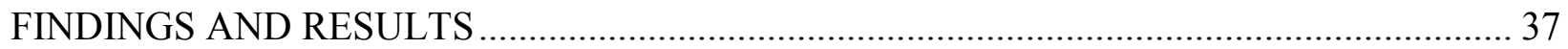

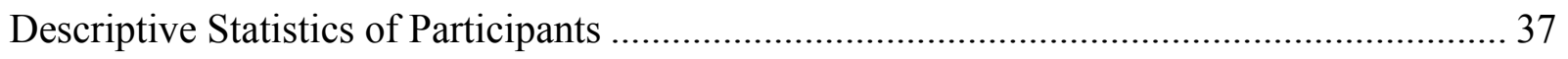

Descriptive Statistics and Reliabilities of Measures ……….................................................. 39

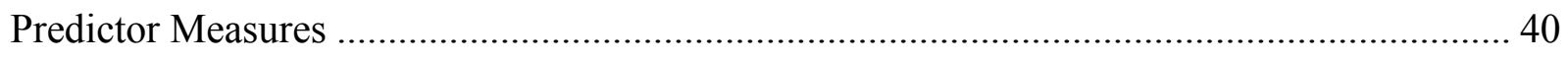

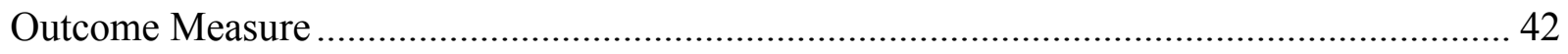

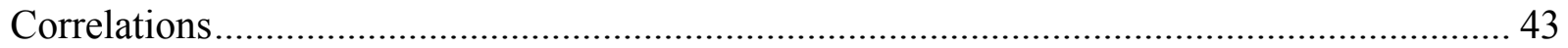

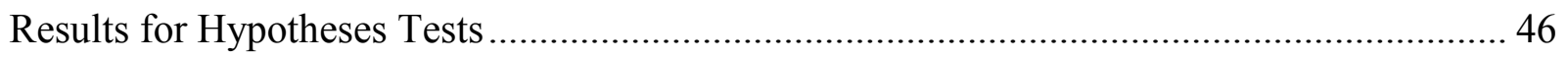

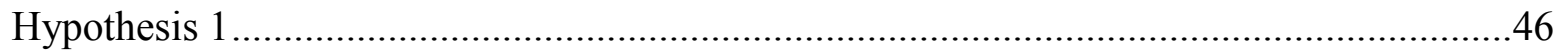

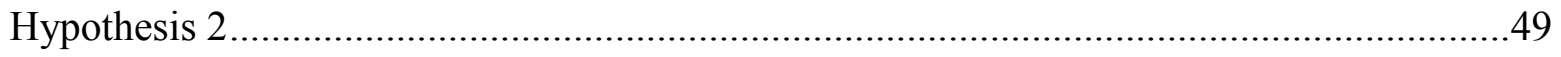

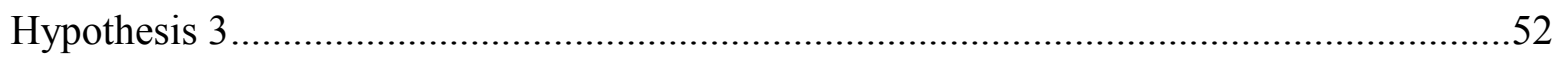

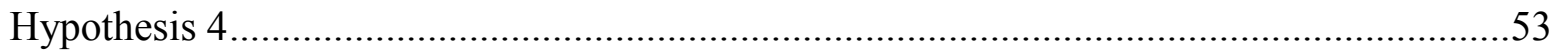

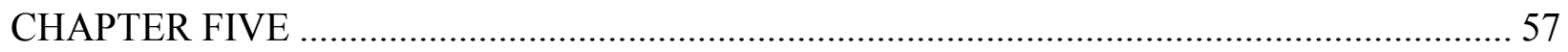

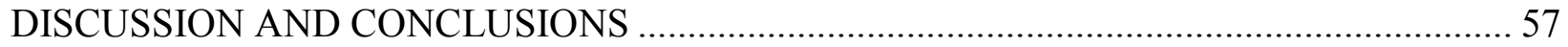


Overview.

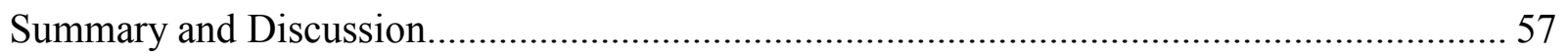

Implications for Research and Practice of Marriage and Family Therapy ........................... 63

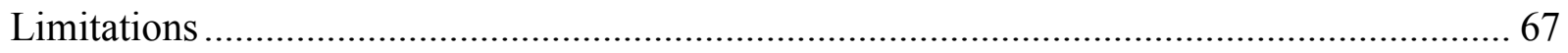

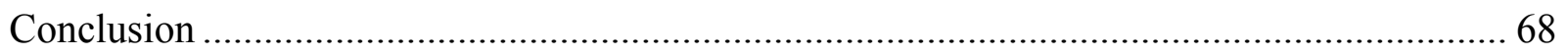

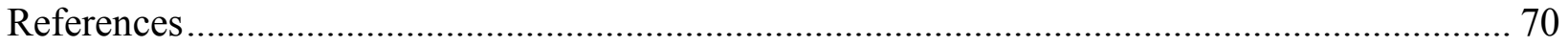




\section{List of Figures}

Figure 3.1. Theoretical Model of Differentiation and IPV ..............................................30 


\section{List of Tables}

Table 4.1 Frequency Distribution of Demographic Variables used in the Differentiation in IPV Model. .38

Table 4.2 Frequency Distribution of Relational Variables used in the Differentiation in IPV Model

Table 4.3 Reported Means, Medians, Standard Deviations and Cronbach's Alpha Scores for Selected Scaled and Sub-Scaled Variables used in the Differentiation in IPV

Model 40

Table 4.4 Zero Order Correlation Coefficients for Selected Domains of the Differentiation in IPV Model with IPV

Table 4.5 Zero Order Correlation Coefficients for Selected Domains of the Differentiation in IPV Model with IPV for Males.

Table 4.6 Zero Order Correlation Coefficients for Selected Domains of the Differentiation in IPV Model with IPV for Females

Table 4.7 Hierarchical Regression Analyses for Influence of Differentiation in IPV Model Predicting IPV from Model Components Depression, Anxiety, and Differentiation for Hypothesis One

Table 4.8 Hierarchical Regression Analyses for Influence of Differentiation in IPV Model Predicting IPV from Model Components Depression, Anxiety, and Differentiation for Hypothesis One Controlling for Males .48

Table 4.9 Hierarchical Regression Analyses for Influence of Differentiation in IPV Model Predicting IPV from Model Components Depression, Anxiety, and Differentiation for Hypothesis One Controlling for Females 
Table 4.10 Hierarchical Regression Analyses for Influence of Differentiation in IPV Model Predicting IPV from Model Components Depression, Anxiety, and Differentiation for Hypothesis Two .50

Table 4.11 Hierarchical Regression Analyses for Influence of Differentiation in IPV Model Predicting IPV from Model Components Depression, Anxiety, and Differentiation for Hypothesis Two Controlling for Males .51

Table 4.12 Hierarchical Regression Analyses for Influence of Differentiation in IPV Model Predicting IPV from Model Components Depression, Anxiety, and Differentiation for Hypothesis Two Controlling for Females .......................................................51

Table 4.13 Results of Differences of Means Testing by Gender for the Differentiation in IPV Model Study Variables .52

Table 4.14 Distribution of Participants by Differentiation of Self Groupings for Cluster Analysis of Differentiation in IPV Model .54

Table 4.15 Means and Standard Deviations of Distribution of Participants by Differentiation of Self Groupings by Gender Using Clustering Effect for ANCOVA Analysis of

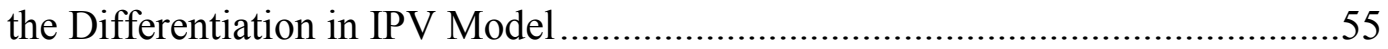

Table 4.16 Factorial ANCOVA Results for Influence of Differentiation in IPV .55 


\section{Acknowledgements}

I take this opportunity to thank several people for their continued support in my journey to achieve this educational goal. Their support helped me accomplish this goal.

I would like to express my deepest appreciation to Dr. Sandra Stith for her interest, dedication, time, and expertise in helping me complete this dissertation. I am grateful to her not only for the help and guidance she provided, but also for the example she showed me though her motivational style and commitment to my success. I would also like to thank Dr. Farrell Webb as co-chair of my committee for his dedication, passion, and expertise at all stages of my dissertation, and for teaching me statistics.

I am indebted to members of the dissertation committee who contributed their time and expertise and supported me throughout this process: Dr. Candyce Russell, Dr. William Meredith at K-State, and Dr. Ryan Peterson at the University of Central Missouri.

My investment in this degree at K-State has been one of the greatest investments for my career. During this journey I had the honor to meet, receive supervision, mentorship and guidance from the unforgettable Dr. Anthony P. Jurich. I had the privilege to also spend a lot of time with Dr. Jurich sharing about our common interests in the field of marriage and family therapy and treatment for individuals and family struggling with substance use disorders. He was always there for me not only as a major professor, but also as a mentor on other issues than just academics. Though he was not able to see me through graduation due to his unexpected passing, I know he is smiling from above knowing that I did it.

Last and most important, I thank my wife and dearest friend Silvana Faja and my wonderful children Maggie, Kevin and Emma. Without their love and support and selfless sacrifices this would not have been possible. 


\section{Dedication}

I dedicate this dissertation to my wonderful wife and best friend Silvana Faja and our three loving and amazing children Maggie, Kevin, and Emma Likcani. Silva completed her doctorate in Management of Information Systems while I was working on my master's degree, and in the meantime we had our first two kids. She consistently supported me to pursue my Ph.D., and when I was accepted into the Ph.D. program, she got pregnant again. Practically we had kids throughout all our graduate studies. We went through both joyous and challenging times, but she was always supportive and encouraging that I earn my doctorate degree.

The start of my Ph.D. studies coincided with the same year that my son Kevin began kindergarten. When he learned that we were both going to school that same year, he asked if we would be riding the same school bus. Silva enjoyed that comment the most because with my return to school now she had to take care of all the kids, including me. My kids contributed to this journey in their own way. They always tried to help me. I enjoyed their contribution through their scribbles and coloring in my books, torn pages from books and papers, and hugs and kisses.

Lastly, I want to thank my extended family for their support and sacrifices during my studies. I thank my sisters Armonela and Eriona and my brother in-law Indrit for always being there for me with their love and support. I thank my parents, Haxhi and Hanke Likcani, who always instilled in me the value of education and invested all they had to make sure that I and my sisters attended the best schools possible. I thank my parents in law, Shyqyri and Sadete Faja, for their support and encouragement. Silva's parents and mine often travelled from Abania to the U.S. to assist us with childcare and house chores as we pursued graduate studies, and for that I am eternally grateful to them. 


\section{CHAPTER ONE}

\section{INTRODUCTION TO THE PROBLEM}

\section{Differentiation and Intimate Partner Violence}

Intimate partner violence (IPV) represents a challenging public health problem in our society. Nearly 3 in 10 women and 1 in 10 men have been subjected to various forms of IPV including physical violence and rape (Black et al., 2011). Domestic violence is an old problem that in the recent decades has received increased attention due to the increased awareness of the injustice of violence and its negative effects on victims. Understanding violence, prevention, and its treatment is an important goal for family scientists and therapists. Its pervasive effects negatively impact all family members as well as the larger community (Stith, Smith, Penn, Ward, \& Tritt, 2004b), and as such must be examined closely.

Research on IPV is scattered across multiple disciplines (sociological, criminological, psychological, legal, medical research) making it difficult to synthesize as well as agree on causes of violence, definitions, or best practices for prevention and treatment. However, all agree that the impact of IPV on victims and on children raised in homes with IPV is negative and that violence is unjust (Barnett, Miller-Perrin, \& Perrin, 2005; Stith, 2006; Stith, McCollum, \& Rosen, 2011). A large body of research has focused on gaining greater understanding of IPV and its devastating effects on individuals, families, and the community (Barnett et al., 2005; Stith et al., 2004b). Despite the growing body of research on the importance of relational factors as predictors of IPV, treatment systems for domestic violence often target the perpetrator alone (Stith et al., 2011) and not the couple or the whole family system. Often the batterers are expected to complete some form of group batterer intervention program for their domestic abuse and victims may access support services through shelters and related programs; however, these 
programs lack the focus on relational dynamics (Stith et al., 2011). This study examined levels of differentiation of self and the impact of these factors on IPV. Findings from this dissertation may inform efforts to target treatment for couples who choose to remain together after experiencing IPV.

\section{Risk Factors for Intimate Partner Violence}

A large body of research exists on risk factors associated with IPV. Stith et al. (2004b) examined evidence from 85 studies to identify risk factors most strongly related to intimate partner physical abuse perpetration and victimization. Their meta-analytic review was guided by Dutton's (1995) nested ecological theory on partner violence, examining factors from micro, meso, and macro perspective. They found that factors more proximal to the violence, in both micro and ontogentic systems are more important in understanding IPV than are factors more distal to the violence. They found large effect sizes between perpetration of physical abuse and five risk factors: emotional abuse; forced sex; illicit drug use; attitudes condoning IPV; and low marital satisfaction. They also revealed a moderate effect sizes between perpetration of physical abuse and six risk factors: traditional sex-role ideology; anger/hostility; history of partner abuse; alcohol use; depression; and career/life stress.

Stith et al. (2000) in another meta-analysis examining support for intergenerational transmission of spouse abuse found that growing up in an abusive family was positively related to perpetrating spouse abuse and to becoming a victim of spousal abuse. Although the strength of both relationships was small to medium, their meta-analysis provided evidence that growing up in families where IPV occurs is a risk factor for becoming involved in a violent marital relationship. 
In a related study on the relationship between attitudes toward violence and attitudes toward gender roles and IPV, Sugarman and Frankel (1996) found a positive relationship between patriarchal attitudes and use of violence. Their findings offered limited support for the ideological component of the patriarchal theory of wife assault and perpetrating violence. Similar relationships were examined by Stith and colleagues (2004b) and produced similar findings. In their meta-analytic investigation she and her colleagues calculated an effect size, $r=.30$, for the relationship between male perpetration and attitudes condoning violence and an effect size, $r$ $=.29$, for the relationship between male perpetration and traditional sex-role ideology.

\section{Differentiation and Intimate Partner Violence}

Bowen's Family Systems Theory is the guiding theory for this study (Bowen, 1978; Kerr \& Bowen, 1988), which is explained in detail in chapter two. Numerous research investigations explored a variety of relational factors that contribute to IPV, but little research exists on the relationship between partner differentiation and IPV, or on the impact of couple differentiation levels on IPV. Differentiation is the ability to separate thoughts and emotions and to activate the intellectual systems which allows for self-regulation of the emotional system. Bartle and Rosen (1994) examined the relationship dynamics of couples in which men had been violent towards their partners. They suggested that lack of individuation ${ }^{1}$ (the initial step toward differentiation) or differentiation may explain why violence is, in part, a distance-regulating mechanism that maintains balance between separateness and connectedness in the relationship. Other research has linked the lack of differentiation and fusion in relationships with IPV (Glickauf-Hughes, Foster \& Jurkovic, 1998; Rosen, Bartle-Haring, \& Stith, 2001; Schubert, Protinsky, \& Veirs,

\footnotetext{
${ }^{1}$ Differentiation vs. individuation: Differentiation is ability to separate thought and emotions and to respond using the intellectual system rather than the emotional system. Individuation is the developmental process of becoming a distinct individual and differentiated from others.
} 
2002). Details of these studies are provided under the literature review section of this dissertation.

\section{Purpose}

The purpose of this dissertation is to evaluate the role of differentiation of self in a relationship on intimate partner violence. This study examined two possible roles of differentiation in the context of IPV. First, I determined if differentiation of self adds to the variance accounted for by the known risk factors, including relational satisfaction, marital conflict, romantic jealousy, depression, anxiety, and attitude about violence towards women.

Second, I examined the moderating effect of gender in the relationship between differentiation of self and IPV, controlling for the known risk factors. Findings from this study add to the literature on differentiation and IPV. Understanding the role of differentiation of self and the relationship of this factor with other risk factors for perpetration can help identify opportunities for prevention and treatment.

\section{Research Question}

To better explain the impact of differentiation of self on IPV the following questions were generated. The research questions are as follows:

1. What role, if any, does differentiation of self play in IPV?

1a. To what extent does mental health (anxiety, depression, and attitudes toward violence) and differentiation influence IPV?

1b. To what extent does relationship quality (relationship satisfaction, marital conflict, romantic jealousy), and differentiation influence IPV?

2. Is there a difference between males and females on level of IPV and risk factors for IPV?

3. Does gender moderate the relationship between differentiation of self and IPV when other known risk factors are controlled? 
In addressing these questions, this dissertation fills gaps in the literature on role of differentiation on IPV. In addition, the findings may inform clinical practice on assessment and treatment interventions for couples presenting with IPV.

\section{Hypotheses}

The hypotheses explore the impact of differentiation on IPV as well as other known risk factors for IPV: relational satisfaction; marital conflict; romantic jealousy; depression; anxiety; and attitude about violence towards women.

One assumption is that lower levels of differentiation of self increase the likelihood for IPV. It is expected that higher levels of perceived differentiation of self are associated with lower levels of IPV. There are three hypotheses that will be tested in this research project. They are listed as follows:

Hypothesis 1 Differentiation of self will have a significant effect on IPV independent of the risk factors of depression, anxiety and attitude towards violence.

Hypothesis 2 Differentiation of self will have a significant effect on IPV independent of the risk factors of relationship satisfaction, marital conflict and romantic jealousy.

Hypothesis 3 Males and females will differ on their levels of IPV, differentiation of self, and other risk factors (depression, anxiety, marital satisfaction, marital conflict, jealousy, and attitudes toward violence).

Hypothesis $4 \quad$ Gender will not impact the relationship between differentiation of self and perpetration of IPV controlling for other risk factors (depression, anxiety, marital satisfaction, marital conflict, jealousy, and attitudes toward violence.

\section{Importance of the Study}

There are several reasons why this research could be considered beneficial. It helps fill in the gaps in the literature on the role of differentiation of self in IPV. Few studies have examined the role of differentiation of self with individuals perpetrating IPV. Findings from this study will add to the body of literature whether level of differentiation of self is another risk factor for IPV 
and the role gender plays in the relationship between self differentiation and perpetration of IPV. Finally, these findings may be used to inform clinical practice on assessment and treatment interventions with individuals and couples presenting with IPV. If we find that an individual's level of differentiation of self in a relationship impacts their level of violence, then it will be important for prevention and treatment programs to work with clients to enhance levels of differentiation. 


\section{CHAPTER 2}

\section{REVIEW OF THE LITERATURE}

There are many important factors associated with the intimate partner violence. In this literature review I shall attempt to discuss those that I believe are directly related to the general thesis of this dissertation - differentiation and the influences of gender differences on the same. To that extent, I have divided this literature review into three sections. In the part one, I examine the literature on intimate partner violence. In the second part, I look at the theoretical constructs, while in part three I present a general focus on risks in intimate partner violence. At all times I am using a gender overlay on the related issues involved in intimate partner violence.

\section{Intimate Partner Violence}

Intimate partner violence (IPV) involves a variety of forms of psychological and physical aggression which occurs between two partners in a marriage or other close relationship. IPV affects everyone. With nearly 3 in 10 women and 1 in 10 men victimized by various forms of IPV (Black et al., 2011), this challenging health problem in our society has devastating effects on victims, families, and communities (Breiding, Black, \& Ryan, 2008; Stith, 2006). The consequences of IPV include negative effects on health and mental health of victims (Breiding et al., 2008; Coker, Davis, Wolfe, et al., 2002; Sutherland, Bybee, \& Sullivan, 1998), financial problems related to assistance necessary for treatment and recovery (Bonomi, Anderson, Rivara, \& Thompson, 2009; Brown, Finkelstein, \& Mercy, 2008), possible challenges for any involvement in the legal system (Jordan 2004), loss of employment or missing work after victimization (National Association of Crime Victim Compensation Boards, 2002; Rothman \& Corso, 2008), with an overall estimated cost of $\$ 8.3$ billion for all associated costs addressed in this paragraph (Max, Rice, Finkelstein, Bardwell, \& Leadbetter, 2004). Domestic violence is an 
old problem that with increased awareness of our society to the injustice of violence and its pervasive effects on everyone, especially on victims and their families. IPV has received increasing attention in the last two decades regarding the understanding of risk factors for violence, prevention, and treatment (Stith, 2006; Stith et al., 2011). The focus of this dissertation is to evaluate the role of differentiation of self in a relationship on intimate partner violence. The following literature review will focus on differentiation and IPV and on risk factors and IPV, and the relationship of risk factors and differentiation as they relate to IPV.

\section{Views on Family Violence}

There are two major perspectives that appear to be on a continuum that explain family violence. Bartle and Rosen (1994) summarized the two perspectives; the feminist perspective on one extreme and the family violence perspective on the other (Kurtz, 1989). According to Bartle and Rosen the family violence perspective includes causal factors such as the intergenerational transmission process, pathology in the perpetrator and/or the victim, and substance abuse to mention a few. The feminist perspective critiques the existing research literature on the lack of inclusion of cultural components such as power differentials between males and females and patriarchal issues, and demands that such contextual issues be included in conceptualizing violence. Bartle and Rosen (1994) make the argument that the family violence and feminist perspectives are not mutually exclusive and encourage a "both/and" approach rather than a onesided reductionist view, as other scholars as have done too (Goldner, Penn, Scheinberg, \& Walker, 1990). Undoubtedly, the feminist movement has positively impacted the field of research, prevention, and treatment of IPV, but as Bartle and Rosen stated "examining this phenomenon from multiple levels provides a more thorough and comprehensive examination of partner violence" (p. 2). There is a growing consensus that multiple factors account for IPV and 
for a need for conceptualizing violence and treating IPV from a comprehensive perspective (Bartle \& Rosen, 1994; Kurst-Swanger \& Petcosky, 2003; Stith, 2006; Stith \& McCollum, 2009; Stith, McCollum, Amanor-Boadu, \& Smith, 2012; Stith, McCollum, Rosen, Locke, \& Goldberg, 2005; Stith, Rosen, McCollum, \& Thomsen, 2004a).

\section{Typologies of Violence}

Stith and colleagues (Stith et al., 2011; Madsen, Stith, Thomsen, \& McCollum, 2012) suggested that not all violence is the same, and that society now conceptualizes IPV more from a scientific perspective than a political one. They suggested that this is one of the most important breakthroughs on understanding of IPV given the growing body of research indicating heterogeneity among couples experiencing IPV. Some of the groundbreaking research came from Michael Johnson and his colleagues (Johnson, 2005, 2006; Johnson \& Ferraro, 2000). They classified heterosexual violence in four main typologies: situational couple violence (also known as common couple violence); intimate terrorism; violent resistance; and mutual violent control. Situational couple violence does not derive from dynamics of control behavior and issues of power, but it is rather considered to derive from situational arguments that find one or both partners lashing out. It is an intermittent pattern of IPV in response to sporadic conflicts (Stith et al., 2011). Intimate terrorism, unlike situational couple violence, is motivated from dynamics of power and control. It may be psychological and/or physical. It may be associated with escalation over time and can lead to serious consequences. It is often not mutual and can be present among people who are emotionally dependent on the relationship (Johnson \& Ferraro, 2000). Violent resistance is considered to be self-defense or a form of resistance to intimate terrorism. Its primary motive is to protect self from perpetrators engaged in intimate terrorism to exert control over the victim. Mutual violent control type of IPV is a form of violence that involves both 
partners being violent towards each other. Although considered rare, it is a battle for control, or as Saunders framed it "mutual combat" (Saunders, 1988).

Be it a bilateral or unilateral form of violence, we know from extensive research that there are a number of factors that contribute to occurrence of IPV (Stith et al., 2012). In this dissertation Bowen's theory provides a platform to conceptualize and better understand IPV.

\section{Part II}

\section{Theoretical Orientation: Bowen Family Systems Theory}

The guiding theory for this dissertation is Bowen's Family Systems Theory. This theory, based on systems theory, was initially developed by Bowen (1978) and further enhanced as a theory by Kerr and Bowen (1988) and Friedman (1991). Family Systems Theory consists of eight interlocking concepts: (1) triangles; (2) nuclear family emotional process; (3) family projecting process; (4) differentiation of self; (5) multigenerational transmission process; (6) emotional cutoff; (7) sibling position; (8) and societal emotional process. Bowen Family Systems theory "is based on the assumptions that the human is a product of evolution and that the human behavior is significantly regulated by the same natural forces that regulate the behavior of all other living things" (p. 3). Bowen conceptualized the family as an emotional unit and used systems thinking to describe interactional patterns in the family. The operation of the

emotional system reflects an interaction between two counterbalancing life forces: individuation and togetherness. Dysfunction is dependent upon the response that people make to an imbalance of individuality and togetherness in a relationship system. Too much distance or too much closeness in a relationship affects the emotional interdependence. Family members influence each other's thoughts, feelings and behaviors. Levels of differentiation determine the type of 
response to the anxiety produced from emotionally-charged situations. Differentiation is the cornerstone of Bowen's theory.

Differentiation. Differentiation is functioning at both the individual and the systemic level. It is the ability to separate thought and emotions (differentiate) and ability to respond using the intellectual system rather than the emotional system. At the intra-psychic or individual level, a differentiated individual has the ability to separate thought from emotions and is able to exercise control over impulses or emotionally-charged situations. At the relationship or interpersonal level, the differentiated individual is able to balance between a separate self and a self connected to others (Bowen, 1966; Friedman, 1991). Friedman (1991) described this process as one of "saying 'I' when others are demanding 'we,' to containing one's reactivity to the reactivity of others" p.141. Bowen (1978) stated that there are two natural forces that act to counterbalance each other in the human relationship systems: a force towards individuality and autonomy; and a force towards togetherness or fusion. Just as these forces are in constant motion, so is the ability of individuals to set boundaries and to maintain separateness of the intellectual and emotional systems. Individuals with a higher degree of differentiation are more likely to maintain reasonable separateness of intellectual and emotional systems. Individuals with low levels of differentiation are characterized by fusion of the intellectual and emotional systems. The greater the fusion, the more difficult it is for individuals to keep emotions in balance, and the more likely it is for them to give in to the emotional pressures of people close to them, thereby causing them to think and act in specified ways.

Kerr and Bowen (1988) explained two notions about differentiation: basic and functional levels of differentiation. Basic level of differentiation is largely determined by the degree of emotional separation from one's family of origin. Functional differentiation is functioning 
dependent on the relationship process and it is influenced by the level of chronic anxiety in a one's most important relationship system. Kerr (1981) described the functional level of differentiation as "shifts in the degree of fusion between the intellectual and emotional systems that are based on shifts in the level of anxiety the person experiences" (p.247).

Differentiation plays an important part in a couple's relationship. A higher degree of fusion can lead a person to lose self in the relationship, eventually leading to what Bowen called 'emotional complementarity' and dependency in the relationship. These dynamics can produce high conflict and eventually emotional cutoff. Among couples living together, emotional cutoff can be accomplished through withdrawal and avoidance of emotionally charged issues while in the presence of the partner. According to Bowen's theory people react by withdrawing, counterattacking, and defending. Bartle and Rosen (1994) suggested that "intuitively, violence would appear to be an exaggerated reactive tendency" (p.225). Gottman (1999) captured these relational dynamics using the metaphor of the 'Four Horsemen of the Apocalypse: criticism; contempt; defensiveness; and stonewalling.

On the other hand, higher levels of differentiation allow partners individuality and autonomy along with the ability to balance and set appropriate boundaries in the relationship. The couple's functional level is influenced by the degree of anxiety in a person's relationship with their partner. When self or partner's level of differentiation is high, the higher the likelihood for couples to deal with conflict appropriately, reduce anxiety, emotional reactiveness, and ultimately reduce chances of triangulation; the process of fusion with another person. Family systems theory teaches people to set clear boundaries. Differentiation of self is what enables an individual to set boundaries for their wellbeing and that of their intimate partner, and allows the other party to do the same (Kerr, 1984; Kerr \& Bowen, 1988). 
Knudson-Martin $(1994,1996)$ expanded the definition of differentiation from her research with women from collectivist cultural backgrounds. She argued that many individuals from less individualistically oriented cultures develop more of a connected self with their family, which could be conceptualized as close to fusion in Bowen's theory. She suggested that differentiation consists of the interplay between the capacity of an individual to function as a solid self and the capacity to orient to others. It is the balance between the development of self through separateness and development of self through connection in the relationship context that determines level of differentiation. Knudson-Martin (2002) stated that "most people are somewhere in the middle and likely to be more in one dimension than the other" (p.117).

Differentiation and IPV. Bowen's Family Systems Theory has been used by some researchers to enhance the understanding of violence in relationships (Bartle-Haring, 1997; Bartle \& Rosen, 1994; Murray, 2006; Rosen et al., 2001). However, research on the relationship of differentiation and IPV is scarce. Only a few studies were identified in the review of literature that examined the relationship between differentiation and IPV. One of the first studies that was found to address differentiation and IPV was conducted by Bartle and Rosen (1994). They examined the relationship of differentiation or individuation and dating violence in the form of case studies using qualitative methods. Their sample consisted of couples in which men had been violent towards their partners. The case studies revealed that lower couple differentiation or individuation was related to IPV. Male batterers turned to violence under stress, when challenged through assertiveness of their partner, and responded to their anxiety through perpetration of IPV. They also discovered the existence of a dichotomy of independence vs. dependence and asserted that: 
... as violence may be a distance-regulating mechanism in the relationship, the relationship may be held together by the male's need to maintain 'masculinity' as being different from his female partner and the female's need to maintain her 'femininity' by maintaining a relationship in which she has invested a great deal. (p. 226)

The authors acknowledged the need for further investigation of differentiation levels, and on fusion and IPV; their study outlined the need for researchers to look at the relationship between differentiation and IPV.

Lack of differentiation may explain why violence is, in part, a distance-regulating mechanism that maintains balance between separateness and connectedness in the relationship (Bartle \& Rosen, 1994). I suggest that lack of differentiation or fusion by one or both partners increases occurrence of IPV among couples. Those with low differentiation depend on others' approval and acceptance, or force others to conform.

Using Bowen's theory, Rosen, Bartle-Haring, and Stith (2001) conducted a study among 411 college students ( 331 women and 80 men) to determine how differentiation of self and family of origin violence (witnessing and or receiving) are related to dating violence, mediated by the level of differentiation in the dating relationship. They compared three models using structural equation modeling: family-of-origin violence and current violence; differentiation levels (self and couple) and current violence; and then all variables combined. Restrictions and missing data limited the sample to 277 (233 women and 44 men). They used Behavioral and Emotional Reactivity Index (BERI) (Bartle \& Sabotelli, 1995) to measure differentiation of self in family of origin, and Differentiation in the Couple Relationships (DIFS-Couple) (Anderson \& Sabatelli, 1992) to assess the level of differentiation in the couple relationship from the individual's perspective. They found that family of origin factors and differentiation of self were 
associated with being a victim or perpetrating violence. The authors also found that couple differentiation accounted for a significant amount of variance in dating violence even when controlling for the amount of variance from family of origin violence factors. Low levels of couple differentiation were found to be associated with a higher likelihood of experiencing IPV in the dating relationships among students (Rosen et al., 2001). Their full model including family of origin factors, differentiation of self in family of origin and couple differentiation accounted for $30 \%$ of the variance in being a victim of current violence and $36 \%$ of perpetrating current violence.

Schubert, Protinsky, and Veirs (2002) examined male-to-female IPV using concepts of Bowen's theory of differentiation and feminist theory. They studied 133 men, where the majority belonged to an anger management group with a history of perpetration of IPV, and the rest formed a control group representative of clients in therapy, individuals from church groups and civic groups, and some from an athletic team. They used the Spousal Fusion/Individuation scale (SPFUS) to measure level of differentiation and fusion between partners. SPFUS is one of the seven scales of the Personal Authority in the Family System Questionnaire (PAFS-Q) measure (Bray, Williamson, \& Malone, 1984). The self-control scale (Sc) of the California Personality Inventory (CPQ) (Gough, 1968) was used to measures the relationship between the "expression of impulse and the management of aggression" (p. 12). The Sex-Role Egalitarianism Scale (SRES) was used to measures sex-role attitudes (Beere, King, Beere, \& King, 1984). They found that among men who perpetrated IPV, higher levels of partner fusion were associated with an increased use of violent conflict tactics among men. More specifically, when they controlled for self-control and marital egalitarianism, fusion was found to be a significant predictor of physical assault. The same was not found for the control group. 
Thus, although some studies have examined the relationship between differentiation and IPV, this study expands earlier research to examine self perceived levels of differentiation and also seeks to determine if levels of differentiation have an impact on perpetration of IPV in addition to known risk factors for IPV.

\section{Part III}

\section{Risk Factors Contributing to IPV}

A large body of research exists on risk factors associated with intimate partner violence (Stith et al., 2008; Stith et al., 2004b; Stith et al., 2000; Sugarman \& Frankel 1996). The risk factors that are a focus of this dissertation are: relational satisfaction; marital conflict; romantic jealousy; depression; anxiety; and attitude about violence towards women. The following section of the literature review will address these factors.

Relational Satisfaction and IPV. There is a strong relationship between IPV and relationship satisfaction expressed in the research literature. Various forms of IPV, including those that do not result in physical injuries, have negative impacts on relationships (Andrews, Foster, Capaldi, \& Hops, 2000; Bradbury \& Lawrence 1999; Madsen et al., 2012; Panuzio \& DiLillo, 2010; Shortt, Capaldi, Kim, \& Laurent, 2010). Even though there is research to support that both males and females are victims of IPV (Archer, 2000; 2002), the consequences of maleperpetrated violence are more destructive to female victims than female-perpetrated IPV towards males (Ackerman, 2012; Stith, et al., 2008). Henning and Connor-Smith (2011) researched the relationship continuity and satisfaction among 1,130 male batterers. In their study they found that men's reports of aggression by their partner predicted lower relationship satisfaction. Their results parallel research on abused women (Koepsell, Kernie, \& Holt, 2006). Ackerman (2012) 
found that female IPV victims are more likely than male victims to experience relational dissatisfaction from IPV inflicted from their partner.

There is evidence in research that relationship satisfaction and IPV have at least two possible relationships. Some researchers have shown that increased relational dissatisfaction or marital discord is a risk factor for IPV (Stith et al., 2008; Stith at al., 2004b; Hotaling \& Sugarman, 1990). Others have shown a relationship between relational satisfaction and IPV (Cano \& Vivian, 2003; Margolin et al., 1998; Stith et al., 2008; Stith et al., 2004b; Vivian \& Malone, 1997). While Stith and colleagues (2008) caution about a cause and effect relationship between these two variables, they provided evidence that such relationships exist. The relationship between IPV and relational dissatisfaction has been consistently evidenced by a number of longitudinal studies (Lawrence \& Bradbury, 2001; Panuzio \& DiLillo, 2010; Schumacher \& Leonard, 2005). Lawrence and Bradbury (2001) revealed that wives in relationships where there was a presence of IPV in the past year were more likely to be maritally distressed and to experience severe relational dissatisfaction at some point over the following four years. This finding was also marginally significant for husbands that were victims of IPV $(\mathrm{p}<.06)$. Panuzio and DiLillo (2010) examined relationships between physical, psychological, and sexual forms of IPV perpetration and victim marital satisfaction over a two year period among 202 newlywed couples. They reported that higher levels of all types of IPV generally were associated with lower levels of relational satisfaction.

Differentiation and Relational Satisfaction. A number of studies have examined the relationship between differentiation and relational satisfaction. Richards (1989) found a significant relationship between differentiation and relational satisfaction. Skowron and Friedlander (1998) reported that individuals with greater levels of self differentiation and less 
emotional reactivity and emotional cutoff, reported higher levels of satisfaction with their partners. In a later study Skowron (2000) examined 118 couples and found that couples with lower levels of fusion or higher levels of differentiation were able to maintain the "I" position in the relationship and experienced higher levels of satisfaction in their marriage. Whereas couples that were characterized by fusion and experienced higher levels of emotional reactivity as a result of fusion and cutoff, reported less satisfaction in their relationship. Lal and Bartle-Haring (2011) examined the relationship between differentiation of self and relationship satisfaction in patients with chronic lung disease and their partners. They found that partner's differentiation of self predicted partner's relationship satisfaction and that patient's relationship satisfaction was positively correlated with partner's relationship satisfaction. Thus, research has consistently found a relationship between differentiation of self and relationship satisfaction; however no previous research has examined the impact that individual or partner differentiation has on the relationship between relationship satisfaction and IPV. The proposed study intends to fill this gap.

Jealousy and IPV. The relationship between jealousy and IPV has been examined in a number of studies (Babcock, Costa, \& Green, 2004; Barnett, Martinez, \& Bluestein, 1995; Hannawa, Spitzberg, Wiering, \& Teranishi, 2006; Wilson \& Daly, 1998; 2001) with jealousy consistently being significantly related to IPV (Babcock et al., 2004; Barnett et al., 1995; Dutton, van Ginkel, \& Landolt, 1996; Fenton \& Rathus, 2010; Puente \& Cohen, 2003; Sugarman \& Hotaling, 1989; Wilson \& Daly, 1998). Jealousy represents intense emotions that may lead to the inability for batterers with low levels of differentiation to employ a response that is free of violence. Research has found jealousy to be a precipitant of IPV where arguments regarding jealousy were associated with violent incidents (Babcock et al., 2004; Fenton \& Rathus, 2010). 
Jealousy and Differentiation. Very little research has examined the relationship between jealousy and differentiation. Glickauf-Hughes et al. (1998) revealed that among other variables, poor self-other differentiation co-occurred with jealousy, possessiveness, patterns of reactivity, and explosive fighting. These findings were consistent with the work of Schubert et al. (2002) who found that higher levels of partner fusion were associated with an increased use of violent conflict tactics among men.

There were also constructs in the literature that addressed this relationship from a theoretical perspective. Schnarch (1997) wrote this about jealousy:

Jealousy is a form or emotional fusion. At its most severe, jealousy illustrates our intolerance for boundaries and separateness from those we love. Our desire to possess our partner is inherently frustrated by the immutable fact that we are two fundamentally separate (though interrelated) people. (p. 64)

Differentiation is a person's ability to have a healthy emotional bond that doesn't allow the individual to act or react at polar opposites; neither compulsively driven to control the other (fusion) nor to run away from the relationship (cut off). Cutting off is not necessarily simply an automatic emotional process due to lack of differentiation; there are elements of choice in the process. According to Bowen that depends on how it is done (Kerr \& Bowen, 1988). Jealousy coupled with lack of differentiation can lead to emotional fusion where boundaries are rigid in the relationship. This study will be able to inform the literature on the relationship between jealousy and differentiation and IPV. My assumption is that the stronger the jealousy and the less differentiated the individual, the higher the likelihood for IPV perpetration to occur.

Depression, Anxiety and IPV. In addition to risk factors mentioned above, some research has pointed out a relationship between mood disorders and IPV when examining 
depression in men who batter. Boyle and Vivian (1996) compared 'clinic men' who sought treatment based on their classification as nonviolent, moderately violent, and severely violent. A control group of non-violent and relationship-satisfied men were also included. All clinic men reported higher levels of depressive symptomatology compared to the sample of men from the community. Men classified as severely violent reported higher levels of depressive symptomatology than nonviolent men. In another study, Vivian and Malone (1997) investigated the relationship between depression and mild to severe husband-to-wife IPV perpetration among a sample of 327 couples who were in marital therapy. They revealed that depression was related to husbands' severe physical IPV perpetration against wives. Maiuro, Cahn, Vitakiano, Wagner, and Zegree (1988) compared domestically violent men to generally assaultive and non-violent men. They reported that there is an increased depressive symptomatology among domestically violent men compared to generally assaultive men and a nonviolent control group. Another study by Pan, Neidig, and O’Leary (1994) found a relationship between depression, family functioning, and aggression. They reported that a $20 \%$ increase in depressive symptomatology in a marital dyad increased the odds of severe aggression by $74 \%$.

Anxiety, though less researched than depression and IPV, has been investigated and found to have a relationship with IPV. Barnett and Hamberger (1992) assessed level of adjustment among 87 maritally violent men compared to 90 maritally nonviolent men. They found that husbands that perpetrate IPV were less well adjusted and more anxious than nonviolent men. Grandin, Lupri, and Brinkerhoff (1998) conducted a study looking at couple violence and psychological distress comparing the mental health of non-victims with victims of physical and psychological violence among 562 couples. They found that both male and female victims of psychological and/or physical violence reported higher levels of depressive symptoms 
compared to non-victims, with females exhibiting higher depression and anxiety scores than their male counterparts. They concluded that being both a perpetrator and victim of either type of violence was associated with significantly higher levels of psychological distress for both genders. Hastings and Hamberger (1998) and Hamberger and Hastings (1991) conducted two studies examining personality characteristics of abusive men. They reported that violent men scored significantly higher than nonviolent men on the anxiety and depression scales. Shuerger and Reigle (1988) investigated characteristics of violent men in treatment for IPV. They reported that violent men in treatment for IPV had higher rates of anxiety and depression compared to the general population. Overall, research has supported that anxiety and depression are risk factors for intimate partner violence.

Depression, Anxiety and Differentiation. Differentiation is a complex matrix of emotional maturity, ability to think logically and rationally when faced with emotional stressors, and ability to maintain balance and closeness in intimate relationships (Bowen, 1978; Kerr \& Bowen, 1988). By virtue of the construct, differentiation was hypothesized by Bowen to be related to distress, anxiety, and depression. Bowen and Kerr articulated that higher levels of differentiation would be associated with increased ability to adapt to anxiety and symptom development, decreased stress, and fewer feelings anxiety (Bowen, 1978; Kerr \& Bowen, 1988). This does not mean that all individuals with poor differentiation levels struggle with psychological functioning, depression or anxiety. It simply means that the higher the level of differentiation, the higher the adaptation abilities, and less the likelihood for individuals and couples to experience depression and/or anxiety symptoms. Kerr and Bowen (1988) wrote the following: 
If circumstances are ideal, even a poorly differentiated relationship can be in balance without that balance being dependent on either person's compromising or accommodating his functioning to relieve anxiety. However, since the probability of a poorly differentiated relationship spawning a significant amount of chronic anxiety is very high, it is much more likely that the relationship balance will be heavily dependent on people's adapting to relieve that anxiety. The lower the level of differentiation, the less people's tolerance for anxiety in themselves and others and the quicker they act to do things to relieve it. So as differentiation decreases, adaptation to relieve or bind anxiety, increase to keep the relationship in balance. (p.79)

Several studies have supported the relationship of differentiation and psychological functioning, more specifically for this dissertation the relationship with anxiety and depression. Lal and Bartle-Haring (2011) examined the relationships among differentiation of self, marital satisfaction, perceived partner support, and depression among 52 patients with chronic lung disease. Among other findings they also found that one partners' differentiation of self and relationship satisfaction predicted the other partners' depression. Kim-Appel, Appel, Newman and Parr (2007) examined the relationship between differentiation of self and psychological symptom status among 227 participants age 62 years and older. They found that the lower the differentiation of self among participants, the higher were the scores for symptoms, which were defined as: somatization; interpersonal sensitivity; depression; anxiety; and hostility. With further analysis they found an inverse relationship between levels of differentiation and symptoms. Lastly, they also revealed that there was no difference across all older age groups, demonstrating that individuals who scored as being less differentiated were significantly more 
likely to report symptoms of distress. In another related study, Elieson and Rubin (2001) examined the relationship between depression and self differentiation among clinically depressed and nondepressed individuals. They revealed that depressed populations have lower levels of differentiation of self than do nondepressed individuals. Their analysis revealed an inverse relationship between depression and differentiation of self.

Chung and Gale (2006) examined cross-cultural differences in the relationship of self differentiation with self-esteem and depressed mood among 427 Korean and 375 European American college students. They found that self differentiation was associated with both of their constructs psychological wellbeing, though with different magnitudes given cultural differences between the two groups. When controlling other factors, they found that self differentiation accounted for $11 \%$ more variance of self esteem and depressed mood for USA participants and $7 \%$ for Korean students. Another finding in their study revealed that the "I" position component of differentiation was a strong predictor of depressed mood and the most powerful predictor of self-esteem when controlling the effect of other components of differentiation. In another study, Murdock and Gore (2004) tested Bowen's construct of differentiation as a predictor for psychological symptoms among 119 students from a Midwestern university. They found that perceived stress, differentiation of self, and their interaction were significant predictors of psychological distress and poor psychological functioning

Johnson and Buboltz (2000) examined the relationship between differentiation of self and psychological reactance among 279 college students. Though 'reactance' was not specified in concrete terms in their study, one can assume that its symptomology is similar to that of anxiety and depressive symptoms. Specifically, their results show that lower levels of differentiation predicted higher levels of psychological reactance. More specifically, "young adults who are less 
able to function in an autonomous and self-directed manner without being controlled, impaired, or feeling responsible for their parents tend to be highly reactant in relation to their freedoms being restricted" p. 98. They also discovered that lower levels of differentiation in relation to their peers seemed to predict higher levels of psychological distress. In a related study, Knauth and Skorwron (2004) along with Knauth, Skorwron and Escobar (2006) examined the effect of differentiation of self on adolescent risk behavior among 363 adolescents in the 2004 study and 161 in the 2006 study. They found that differentiation of self mediated the relationship between chronic anxiety and symptom development, indicating that greater differentiation of self predicted fewer symptoms (Knauth \& Skorwron, 2004). Knauth et al. (2006) similarly found that differentiation of self was negatively related to chronic anxiety, and that differentiation of self enables adolescents to manage chronic anxiety thus resulting in adaptive coping skills and less involvement in risk behaviors.

Thus, in addition to Bowen theory predicting that differentiation would be related to distress, differentiation of self has been examined in a number of research studies and has been shown to be related to anxiety and distress for older and younger people and for healthy and ill individuals.

Attitudes about Violence towards Women and IPV. Former First Lady Abigail Adams wrote the following to her husband President John Adams (Adams, 2004):

I long to hear that you have declared independency. And, by the way, in the new code of laws which I suppose it will be necessary for you to make, I desire you would remember the ladies and be more generous and favorable to them than your ancestors. Do not put such unlimited power into the hands of the husbands. Remembers, all men would be tyrants if they could. If particular care and 
attention is not paid to the ladies, we are determined to foment a rebellion, and will not hold ourselves bound by any laws in which we have no voice or representation. ... Men of sense in all ages abhor those customs which treat us only as the vassals of your sex; regard us then as beings placed by Providence under your protection, and in imitation of the Supreme Being make use of that power only for our happiness. (pp. 149-150)

To say that we have made progress in equality of rights between men and women is a statement of male privilege. It is distressing to recognize that some people still approve of violence against women in the western civilized society, but it is true. Historians of domestic violence have addressed the challenges of women's rights in our male dominated society and patriarchal attitudes to develop institutional rights in response to wife beating; and find their battle to have many challenges (Bloch, 2007). Feminist literature suggests that patriarchal attitudes pervade our culture and endorse IPV perpetrated by men (Schubert et al., 2002; Walker, 1996).

Although most of the recent studies on attitudes supporting violence against women focus on examining attitudes of men in non-western societies (Diop-Sidibe, Campbell, \& Becker, 2005; Haj-Yahia, 2000, 2003; Khawaja, 2004; Khawaja, Linos, \& El-Roueiheb, 2008), attitudes approving violence against women have been found to continue to persist in our country (Johnson, 1995; Straus, Gelles, \& Steinmetz, 1980; Walker, 1989, 1996; Yllo, 1993; Yllo \& Straus, 1990). Attitudes and beliefs about violence towards women and wife beating have been regarded as important for understanding factors that cause and perpetuate IPV and have been documented as risk factors for IPV (Gelles \& Harrop, 1989; Gelles \& Straus, 1988; Saunders, 1988; Saunders, Lynch, Grayson \& Linz, 1987; Straus, 1980; Tjaden, \& Thoennes, 2000). 
Gender and IPV. Research has shown that IPV is complex, and also that it is not necessarily a men's domain alone. Stith and colleagues (2011) asserted that explanation of IPV simply from a patriarchal perspective meaning that men perpetrate violence on women to exert control is called into question. Research on IPV has primarily focused on men's perpetration of violence and female victims (Stith et al., 2008), in large part due to access to male batterers because males were the ones court-ordered to treatment programs in the past. Stith stated that "we are currently seeing both men and women court-ordered to treatment for acts of aggression" p. 12. Clearly most violence is perpetrated by men (Black et al., 2011) and the severity of levels and rates of IPV is higher for men (Archer 2000; 2002; Stith et al., 2008; Tjaden \& Theonnes, 2000). However, research has shown that both men and women perpetrated IPV (Archer, 2000; 2002; Kelly \& Johnson, 2008; Stith \& Straus 1995). Given the complexities of IPV, research indicating that both genders perpetrate IPV, and the research on subtypes of IPV (Johnson, 2005, 2006; Johnson \& Ferraro, 2000), I suggest that males and females do not differ on their levels of IPV.

Gender and Differentiation. Bowen (1978) asserted that no gender differences exist on levels of differentiation. There is little and inconclusive research on gender differences on expression of differentiation. For example, Skowron and Friedlander (1998) reported that some elements of differentiation measured by the Differentiation of Self Inventory showed preliminary gender differences with women reporting greater Emotional Reactivity than did men, but no gender differences were observed in Emotional Cutoff. However, the authors cautioned on interpretation of results due to an unequal sample size of men and women and significant gender differences on level of education with men reporting higher levels than women. On the other hand, Bartle-Haring \& Probst (2004) in their study on emotional reactivity and psychological 
distress found no gender differences for males and females on paths between emotional reactivity and stress and psychological distress. Given the limited research on gender differences on differentiation, and their focus being more on level of differentiation of self from family of origin, there is not enough evidence disprove nor support Bowen's assertion that levels of differentiation are not affected by gender. The focus of this study is on differentiation of self in a relationship, as measured by Differentiation in the Couple Relationship Scale (DIFS-Couple, Anderson \& Sabatelli, 1992). I suggest that there are no gender differences on levels of differentiation. Theoretically, differentiation is a process to achieve and maintain balance. As indicated by Bartle-Haring and colleagues (2002; 2004), and Skowron and Friedlander (1998), expression of differentiation may be different depending on multiple factors from family of origin (Friedman, 1991), or age also suggested by Skowron and Friedlander (1998), and may not be related to gender. Certainly this is an area that deserves more research.

\section{Conclusion}

Intimate partner violence continues to be an issue that impacts families and communities in our society. This dissertation was guided by Bowen's Family Systems theory. It examined the impact of level of differentiation of self on IPV and the role of gender on the relationship between differentiation of self and perpetration of IPV, controlling for other factors. It is clear from the review of literature that Bowen's Family Systems theory can help us to enhance our understanding of IPV, but it is also evident that very little research exists examining the role of differentiation in IPV. Findings from this research add to the body of literature on IPV, enhance understanding of risk factors and IPV, and may inform prevention and treatment efforts for IPV. 


\section{CHAPTER THREE}

\section{RESEARCH METHODOLOGY}

The primary purpose of this dissertation was to evaluate the role of differentiation in relationship to Intimate Partner Violence (IPV). In short, I examined whether differentiation of self in a relationship adds to the variance accounted for by the known risk factors, including relational satisfaction, marital conflict, romantic jealousy, depression, anxiety, and attitude about violence towards women. The second objective was to examine the effect of gender on the relationship between differentiation of self and IPV, controlling for the other factors. The final objective of this study was to determine what was the effect of gender on perpetration of IPV and other known risk factors examined by the Differentiation of IPV Model used in this investigation.

Although literature on risk factors for IPV is extensive, research that examines the role of differentiation of self on IPV is scarce. The existing literature has made the case that differentiation may be another predictor for perpetration of IPV. Findings in this research project add to the literature by providing a more in depth view of IPV when the role of differentiation of self in a relationship is identified.

\section{Research Questions}

The research questions in this dissertation were generated from my interest in examining the role of differentiation on IPV. They are influenced by my attempt to examine IPV from a Bowen family systems perspective and to add to the existing literature on role of differentiation in IPV. To better explain the impact of differentiation of self on IPV the following questions were generated. The questions are as follows:

1. What role, if any, does differentiation of self play in IPV? 
1a. To what extent does mental health (anxiety, depression, and attitudes toward violence) and differentiation influence IPV?

1b. To what extent does relationship quality (relationship satisfaction, marital conflict, romantic jealousy) and differentiation influence IPV?

2. Is there a difference between males and females on level of IPV and risk factors for IPV?

3. Does gender moderate the relationship between differentiation of self and IPV when other known risk factors are controlled?

In addressing these questions, this dissertation fills gaps in the literature on role of differentiation on IPV. In addition, the findings can be used to inform clinical practices on assessments and treatment interventions for individuals and couples presenting with IPV.

\section{Research Hypotheses}

The hypotheses developed for the purpose of this dissertation explore the role of differentiation on IPV and other risk factors for IPV including relational satisfaction, marital conflict, romantic jealousy, depression, anxiety, and attitude about violence towards women. The hypotheses in this dissertation are supported by both theory and research and they evaluate the issues identified in the research questions. The hypotheses are stated in such a way as to clearly identify the effect of differentiation on IPV. There are several assumptions in these hypotheses. One assumption is that differentiation may be a risk factor for IPV. Stated differently, one can say that lower differentiation of self increases the likelihood for IPV. Another assumption is that males and females would differ on levels of violence and on other risk factors. Lastly, I believe that higher perceived differentiation of self is associated with lower levels of IPV. There are three hypotheses that will be tested in this research project. They are listed as follows:

Hypothesis 1 Differentiation of self will have a significant effect on IPV independent of the risk factors of depression, anxiety and attitude towards violence. 
Hypothesis 2 Differentiation of self will have a significant effect on IPV independent of the risk factors of relationship satisfaction, marital conflict and romantic jealousy.

Hypothesis 3 Males and females will differ on their levels of IPV, differentiation of self, and other risk factors (depression, anxiety, marital satisfaction, marital conflict, jealousy, and attitudes toward violence).

Hypothesis $4 \quad$ Gender will not impact the relationship between differentiation of self and perpetration of IPV controlling for other risk factors (depression, anxiety, marital satisfaction, marital conflict, jealousy, and attitudes toward violence).

Following is a theoretical model of differentiation and IPV used in this study.

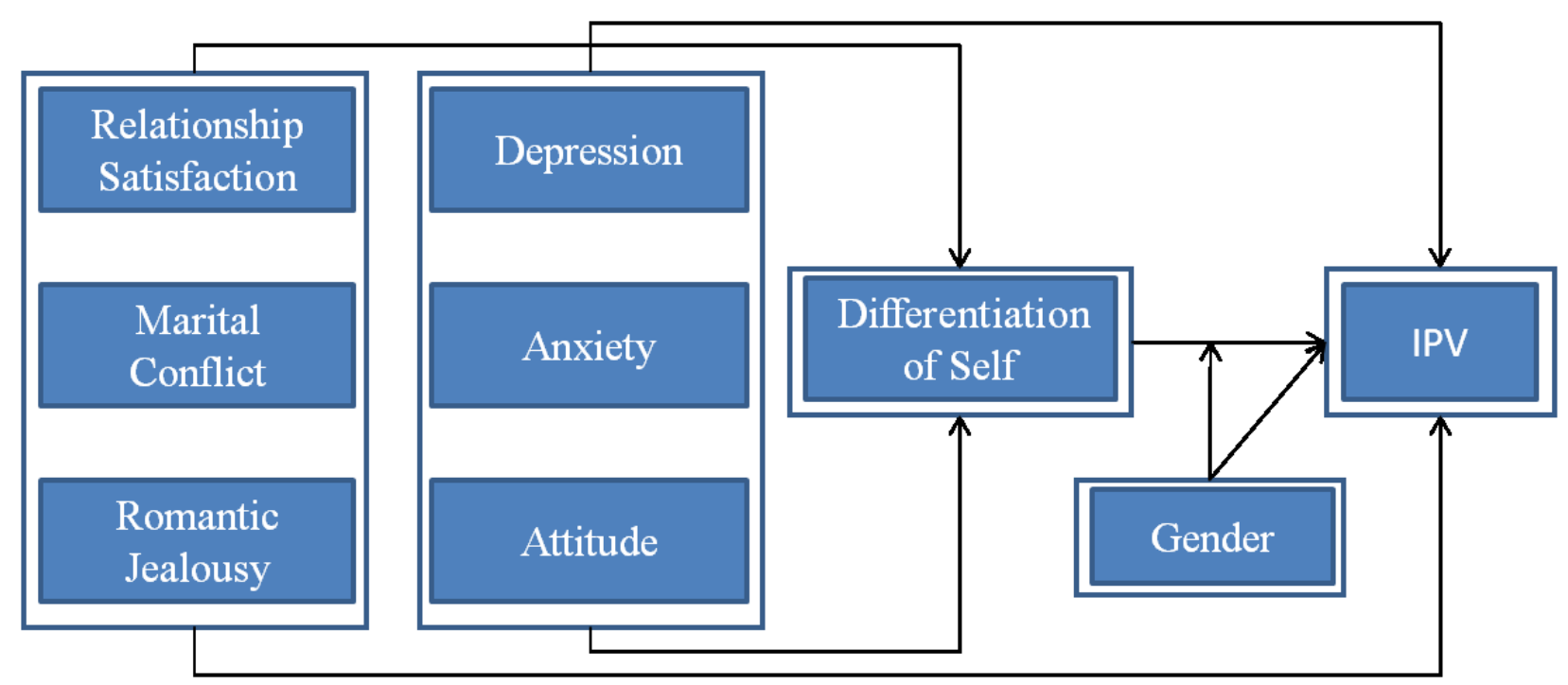

Figure 1. Representation of the impact of differentiation on IPV controlling for other known risk factors and the effect of gender on the relationship between differentiation and IPV.

\section{Data}

The data used in this study were gleaned from the Domestic Violence-Focused Couples Treatment Project, (DVFCT) (Stith et al., 2011; 2005) an NIMH-funded treatment program for couples who wanted to stay together after experiencing IPV. This was a five-year project designed to develop and pilot test an integrated, systemic domestic violence-focused couples treatment program in both individual and multi-couple group formats. 
Couples referred to the program primarily came from the Washington DC metropolitan and Northern Virginia area. Referrals to the program were made by the Probation Officers, local domestic violence treatment providers, therapist and attorneys. Upon referral, couples completed pre-test data and a series of assessment tools to determine eligibility and appropriateness for the project. For the purpose of this dissertation data from a total of 410 participants were used that consisted of equal numbers of 205 females and 205 males - this is true since the couples were all in heterosexual relationships.

\section{Measures}

Participants completed a number of questionnaires as part of study's pre-test screening procedure. The measures completed, along with the basic demographics of age, gender, race, level of education, employment, and income as well as status and length of relationship, that were used for the purpose of this dissertation are described below. They have been divided into

the predictor measures, those used as independent factors in the proposed study and the outcome measure, the element that I am trying to predict, or in standard parlance, the dependent variable.

\section{Predictor Measures}

Differentiation of Self was based on the The Differentiation in the Couple Relationship Scale (DIFS-Couple, Anderson \& Sabatelli, 1992). This instrument consists of 22 Likert-type items assessing levels of differentiation in the couple relationship. DIFS-Couple consists of two parts: self differentiation with 11 items; and partner differentiation with 11 items - this scale measures the respondent's perception of their partner's level of differentiation. Only differentiation of self was used in this study. Some of the items for differentiation of self include: "I tell my partner what he/she should be thinking" and "I allow my partner to speak for him/herself." 
Relationship Satisfaction. The Kansas Marital Satisfaction scale (KMSS) was used to assess relationship satisfaction. This scale consists of three items rated on a scale ranging from 1 (extremely dissatisfied) to 7 (extremely satisfied). Schumm, Nichols, Schectman, and Grisby (1983) report scale reliabilities ranging from $[\alpha]=.89$ to .98 and a test-retest reliability over a 10 week period of $[\alpha]=.71$. In addition, the KMSS was significantly correlated with the Quality of Marriage Index and with the Dyadic Adjustment scale (Schumm, et al., 1983).

Level of Marital Conflict (Straus, Gelles, \& Steinmetz, 1980). This instrument is a selfreport questionnaire that consists of five Likert-scale items. The items measure five issues which are frequent sources of conflict in marital relationships: finances; housework; social activities; sex; and children. Frequency of conflict is measured on a 5-point scale ranging from "Always" to "Never" on frequency of marital conflict on these items. Scoring consists of adding up all responses and dividing them by five. The higher the score, the greater the marital conflict. If the question on children does not apply, the total score is divided by four.

Romantic Jealousy was measured using Relationship Jealousy Scale. This scale was developed by White (1981) to assess respondent's view of himself or herself as "jealous or not jealous in the current relationship." The instrument consists of six questions, some measured on a 7-point Likert scale and the other on a 5-point Likert scale. Some of the questions were: "In general, how jealous of a person do you think you are?" and "How jealous do you get of your partner's relationship with members of the opposite sex?"

Depression and Anxiety. The depression and anxiety subscales were borrowed from the SCL-90-R developed by Derogatis and Melisaratos (1983). The depression scale consists of 13 self-report questions. The anxiety scale consists of 10 questions. Each subscale is rated on a 5- 
point scale of distress (0-4), with number zero representing "not at all" at one end and number four representing "extremely" at the other end.

Attitude towards Violence was measured using the Inventory of Beliefs about Wife Beating (IBWB). The IBWB (Saunders, Lynch, Grayson, \& Linz, 1987) was used to measure participants' beliefs and attitudes about the acceptability of wife beating. It contains 31 items in

five subscales. For this study the "Wife Beating is Justified" scale will be used consisting of 12 items. An item in this scale is "Episodes of a man beating his wife are the wife's fault." Each item was rated on 7-point Likert-type scale $(1=$ strongly agree, $7=$ strongly disagree $)$, the lower the score, the higher the justification of violence towards wives.

\section{Outcome Measure}

The outcome measure, shown in the model as Intimate Partner Violence was measured by a scaled variable based on the Conflict Tactics Scale, Revised (CTS2). It, the CTS2, is the most widely used measure of partner violence. Conflict Tactic Scale (CTS) was originally developed by Straus (1979) and CTS2 is the revised version developed by Straus, Hamby, Boney-McCoy and Sugarman (1996). The CTS2 has five subscales. Two of the CTS2 subscales were used in the present study: Minor Physical Aggression (5 items; e.g., "I pushed or shoved my partner"); and Severe Physical Aggression (7 items; e.g., "I used a knife or gun on my partner"). For the pretest, participants were asked to report how often their partner had committed each act in the past year $(0=$ never, $1=1$ time, $2=2$ times, $3=3-5$ times, $4=6-10$ times, $5=11-20$ times, $6=$ more than 20 times).

\section{Plan of Analysis}

The analysis proceeded from the more general to the more specific. To that end, I began by using simple descriptive statistics to understand the sample. I used univariate, bivariate, and 
multivariate statistics in order to examine the research hypotheses. To test the third hypothesis I used a series of t-tests to determine the difference of means scores for men and women. The other hypotheses were tested using hierarchical regression analyses and two-way Analysis of Covariance (ANCOVA) that allowed me to test the relationships among variables as depicted in the model with intimate partner violence as the outcome measure.

Prior to creating the composite variables and conducting the statistical tests described below, I recoded several reverse-scored items to ensure that all items in the composite scales are coded in the same direction. For one of the measures, the standardization procedure was necessary because the items varied in how they were measured. Some of the items were measured in a Likert-scale one to seven while the others ranged from one to five. Standardization procedure was conducted to avoid the discrepancy where items with a range of one to seven would determine the outcome of the overall scale more heavily than the items with the smaller range of one to five.

Univariate Statistics. In this study, simple descriptive analyses of the sample were conducted. Basic frequency distributions and measures of dispersion (mean, medians, modes, standard deviations, and variances) were examined to provide a general picture of the sample. Univariate cluster analysis was also used to create groups of study subjects based on their level of differentiation of self. These groupings were then used in the Analysis of Covariance (ANCOVA) along with gender groupings to test the third hypothesis.

Bivariate Statistics. Simple zero order correlation tests were used to explore correlations among study variables. In addition, the nature of this study required that the mean differences between the groups be examined in detail, specifically those regarding sex (gender). Simple 
difference of means testing (t-test) was done initially to answer the third hypothesis and determine if there are factors on which men and women differ.

Multivariate Statistics. Hierarchical regression was used to test hypotheses one and two represented in the model. The unique contribution of differentiation in the explanation of IPV was assessed through multiple regression analyses. First, I entered into the model the known risk factors for IPV (relational satisfaction, marital conflict, romantic jealousy, depression, anxiety, and attitude about violence towards women) based on the model. For the first hypothesis, depression, anxiety, and attitude about violence towards women were entered first, and differentiation was entered in a second block in the analysis. For the second hypothesis, relational satisfaction, marital conflict, and romantic jealousy were entered first, and differentiation was entered in a second block in the analysis. This allowed me to explore the effect of differentiation on IPV above and beyond the effect of the known risk factors that were entered in block one.

To test hypothesis three, I conducted independent samples t-tests. For each test, gender was the independent variable and one of the study variables was the dependent variable. These tests allowed me to analyze the significance of difference between males and females in all study variables (IPV, differentiation of self, relational satisfaction, marital conflict, romantic jealousy, depression, anxiety, and attitude about violence towards women). For hypothesis four, Analysis of Covariance (ANCOVA) was used to examine the effect of gender on IPV when controlling for other risk factors as well as the role of gender in the relationship of differentiation of self and IPV. This method was used to compare values of IPV for each gender group and for different levels of differentiation of self and allowed me to control for the other known risk factors that are 
considered in this study, in order to isolate the effects of gender and differentiations of self on IPV. 


\section{CHAPTER FOUR}

\section{FINDINGS AND RESULTS}

In this chapter I present the results of statistical analyses performed on the data used for this study. The chapter consists of three sections. The first section provides detailed data about the sample population. The second section provides preliminary analyses such as reliabilities and descriptive statistics of measures used in this dissertation while the third section consists of results of the data analysis used to answer the research questions and the study hypotheses.

\section{Descriptive Statistics of Participants}

A total of 410 participants were included in the sample analyzed for this dissertation: 205 females and 205 males as shown in Table 4.1. The majority of participants (40.3\%) belonged to the age group of 25 years of age to 34 years of age. ${ }^{2}$ The majority of participants who reported their racial background were White (43.9\%), followed by Blacks (31.2\%) and Hispanics (11.7\%) as the two largest minority groups represented in this sample. It is interesting to note that the level of education was not reported by more than one-third (37.0\%) of the participants. However, among those who did report their education approximately ten percent $(10.1 \%)$ had less than high school education, $24.5 \%$ had earned a high school diploma or equivalent and $28.0 \%$ had some college education. The remaining sample indicated that $37.3 \%$ earned a bachelor's degree or higher. ${ }^{3}$ Employment was another demographic variable considered for this descriptive analysis. The majority of participants (67.8\%) reported that they were employed fulltime, $12.4 \%$ were employed part-time, and the rest were not in the workforce.

\footnotetext{
${ }^{2}$ Since there was not an interval level age measure the ordinal level measure only allows me to provide information in this aggregated form.

${ }^{3}$ The higher levels of education among the sample were somewhat inconsistent with previous investigations; however, given the region of the country from where the sample was collected these unique circumstances may account for the findings.
} 
Table 4.1

Frequency Distribution of Demographic Variables used in the Differentiation in IPV Model.

\begin{tabular}{|c|c|c|c|}
\hline Variables & Characteristics & $n$ & $\%$ \\
\hline \multirow[t]{2}{*}{ Gender } & Female & 205 & 50.0 \\
\hline & Male & 205 & 50.0 \\
\hline \multirow[t]{6}{*}{ Age } & $18-24$ & 43 & 13.7 \\
\hline & $25-34$ & 127 & 40.3 \\
\hline & $35-44$ & 92 & 29.2 \\
\hline & $45-54$ & 41 & 13.0 \\
\hline & $55-64$ & 8 & 2.5 \\
\hline & Over 65 & 4 & 1.3 \\
\hline \multirow[t]{7}{*}{ Race } & White & 162 & 43.9 \\
\hline & African American & 115 & 31.2 \\
\hline & Hispanic & 43 & 11.7 \\
\hline & Asian & 21 & 5.7 \\
\hline & Mixed Race & 17 & 4.6 \\
\hline & Native American & 1 & 0.3 \\
\hline & Other & 10 & 2.7 \\
\hline \multirow[t]{7}{*}{ Education } & Less than high school & 26 & 10.1 \\
\hline & High School/GED/Vo-Tech & 63 & 24.5 \\
\hline & Some College & 72 & 28.0 \\
\hline & Bachelors & 34 & 13.2 \\
\hline & Some grad school & 15 & 5.8 \\
\hline & Master's & 32 & 12.5 \\
\hline & Doctorate & 15 & 5.8 \\
\hline \multirow[t]{5}{*}{ Employment Status } & Full-time & 246 & 67.8 \\
\hline & Part-time & 45 & 12.4 \\
\hline & Student & 16 & 4.4 \\
\hline & Home with kids & 25 & 6.9 \\
\hline & Unemployed & 31 & 8.5 \\
\hline
\end{tabular}

Income data were not consistently reported and as a result nearly two-fifths (44\%) of participants in this study neglected to provide information. Of the 231 participants who did report their income, almost a third (32.9\%) of them had an annual income in the range $\$ 20,000$ to $\$ 40,000$ and $30.3 \%$ had an income above $\$ 40,000$ per year. A little more than one-quarter 
(26.0\%) of those who had an income, reported annual incomes below $\$ 20,000$. About $10.8 \%$ reported they had no earned income.

Table 4.2 presents descriptive statistics for two additional variables, relationship status and duration. Approximately $88 \%$ (87.7\%) reported living together with their primary partner. Relationship duration was divided into four groups, the largest being those who had been in a relationship for less than five years $(60.0 \%)$. Among those who have been in a relationship for six to ten years was approximately one-quarter (24.3\%). The remaining $15.3 \%$ were in relationships of 11 or more years with almost one-third of that group (4.3\%) being in very long term relationships of 20 or more years.

Table 4.2

Frequency Distribution of Relational Variables used in the Differentiation in IPV Model

\begin{tabular}{llrr}
\hline Variables & Characteristics & $n$ & $\%$ \\
\hline Relationship Status & Together & 300 & 87.7 \\
& Apart & 42 & 12.3 \\
Relationship Duration & & & \\
& $0-5$ & 222 & 60.0 \\
& $6-10$ & 90 & 24.3 \\
& $11-20$ & 42 & 11.4 \\
& Over 20 & 16 & 4.3 \\
\hline
\end{tabular}

\section{Descriptive Statistics and Reliabilities of Measures}

This section provided results of tests regarding reliabilities and other descriptive statistics of measures used in this study. The results of the reliability tests are provided in Table 4.3. Reliability scores that are 0.70 or greater are considered as valid and acceptable (George \& Mallery, 2010). All measures in this study ranged from 0.70 (acceptable) to 0.95 (excellent). There were some missing data for all of the scales, nevertheless the validity of the scales were maintained as is shown in the results. 
Table 4.3

Reported Means, Medians, Standard Deviations and Cronbach's Alpha Scores for Selected Scaled and Sub-Scaled Variables used in the Differentiation in IPV Model

\begin{tabular}{llccccc}
\hline Measure & Range & Mean & Mdn & sd & $\alpha$ & $n$ \\
\hline Differentiation of Self & $1-5$ & 3.74 & 3.73 & 0.50 & 0.74 & 270 \\
Relationship Satisfaction & $1-7$ & 4.01 & 4.00 & 1.60 & 0.95 & 319 \\
Marital Conflict & $1-5$ & 3.09 & 3.25 & 0.87 & 0.74 & 271 \\
Romantic Jealousy (standardized) & $1-5,7$ & 0.00 & -0.14 & 0.82 & 0.90 & 307 \\
Depression & $0-4$ & 1.37 & 1.23 & 0.91 & 0.91 & 303 \\
Anxiety & $0-4$ & 0.78 & 0.40 & 0.91 & 0.94 & 312 \\
Attitude toward violence & $1-7$ & 1.83 & 1.58 & 0.82 & 0.74 & 302 \\
IPV & $0-6$ & 0.36 & 0.20 & 0.46 & 0.86 & 305 \\
$\quad$ Minor Physical Aggression & $0-6$ & 0.98 & 0.60 & 1.13 & 0.85 & 313 \\
$\quad$ Severe Physical Aggression & $0-6$ & 0.22 & 0.00 & 0.42 & 0.70 & 310 \\
\hline
\end{tabular}

\section{Predictor Measures}

Differentiation of Self. The construction of the Differentiation of Self scale consists of 11 Likert-type items assessing levels of differentiation of self in the couple relationship. Each represents a statement describing the relationship between the respondent and their partner. The response scale ranges from 1-“Never” to 5-“Always" indicating level of agreement with the statement. Some of the items were re-coded so that the high number indicated a more positive outcome. The overall measure reliability was $[\alpha]=.74$. Furthermore, the reliability tests were conducted for each gender group. The reliability of the measure for males was $[\alpha]=.71$ and for females was $[\alpha]=.78$.

Relationship Satisfaction. The construct of relationship satisfaction consists of three items that make up the Kansas Marital Satisfaction Scale that assess relationship satisfaction. Each item was rated on a scale ranging from 1 (extremely dissatisfied) to 7 (extremely satisfied). 
In this study, internal consistencies for the scale were high. For the entire sample $[\alpha]=.95$. For males reliability was $[\alpha]=.94$, and for females it was $[\alpha]=.96$.

Marital Conflict. The scale for marital conflict consisted of four Likert-scale items. The marital conflict is measured on a 5-point scale ranging from 1-"Always" to 5-"Never" on frequency of agreement about finances, housework, social activities, and sex. In short, the higher the score, the greater the marital conflict. Reliability test for the entire sample was $[\alpha]=.74$, for males it was $[\alpha]=.80$ and for females was $[\alpha]=.60$.

Romantic Jealousy. This construct was measured through six questions. Four of the questions were measured on a 7-point Likert scale ranging from 1-"Not at all jealous" to 7-"Very jealous." Two other items represented how often one becomes jealous and were measured on a 5point scale ranging from 1-"Never" to 5-"Often." Therefore, the higher the scores, the higher the level of jealousy.

However, since the six items in this construct were measured in different units of measurements, standardized scores were used instead of the original values for the items. The reliability of the scale for the sample was $[\alpha]=.90$. The reliability for males and females was the same at $[\alpha]=.90$.

Depression. The depression subscale was comprised of 13 items from the $S C L-90$ Depression and Anxiety Subscales. Each item was rated on a 5-point scale of distress (0-4), with number zero representing "Not at all" at one end and number four representing "Extremely" at the other end. The reliability for depression subscale for the total sample was $[\alpha]=.91$. The reliability for males was $[\alpha]=.92$ and for females it was $[\alpha]=.91$.

Anxiety. The construct of anxiety consisted of 10 items from the SCL-90 Depression and Anxiety Subscales. Each item was measured on a 5-point scale of distress (0-4), with number 
zero representing "Not at all" and number four representing "Extremely." The reliability for anxiety for the entire sample was $[\alpha]=.94$. The reliability for males was $[\alpha]=.94$ and for females it was $[\alpha]=.94$.

Attitude Toward Violence. This construct consisted of 12 items measuring beliefs and attitudes about the acceptability of wife beating from the Inventory of Beliefs about Wife Beating $(I B W B)$. Each item was rated on 7 -point Likert-type scale (from $1=$ Strongly agree, to $7=$ Strongly disagree). Seven items were re-coded so that the items had consistent meaning: the lower the score, the higher the justification of violence towards wives/partners. Reliability for the entire sample $[\alpha]=.74$. Reliability for male respondents was $[\alpha]=.76$, and for female respondents was $[\alpha]=.71$.

\section{Outcome Measure}

Intimate Partner Violence. The outcome measure, physical Intimate Partner Violence, was assessed with five items measuring minor physical assault and seven items measuring severe physical assault, both subscales of the Conflict Tactics Scale, Revised (CTS2). In the original scale items are scored on a 8-point Likert scale where numbers 1 through 6 represented an increasing intensity of assault episodes from 1="Once" to 6="More than 20 times" in the past year, whereas, 7 measured "Not in the past year, but it happened before" while the number zero was used to indicate that it "Never" occurred. For the purpose of this study the items were recoded on a 7-point Likert scale from zero to six so that the high number indicated a more negative outcome $(0=$ Not in the past year, but it happened before; $1=$ Once; $2=$ Twice; $3=3-5$ times, $4=6-10$ times, $5=11-20$ times, and $6=$ more than 20 times). The physical IPV outcome measure for this study was computed by combining the subscales of minor and severe physical assault into one single measure. The minor physical assault subscale was weighted at 0.50 before 
it was combined with the severe physical assault subscale to compute the physical IPV measure. The rationale for weighting the items for minor physical assault was to adjust for high scores on this subscale against high scores on the subscale of severe physical assault, given the difference of severity of assault measured by the two subscales. Reliability tests were conducted for both subscales separately and for the combined single measure of physical IPV. The reliability for respondents' Minor Physical Assault for the entire sample was $[\alpha]=.85$, for males it was $[\alpha]=$ .85 , and for females the reliability was $[\alpha]=.86$. Whereas reliability for Respondents' Severe Physical Assault for the entire sample was $[\alpha]=.70$, for males it was $[\alpha]=.74$, and for females reliability was $[\alpha]=.70$. The reliability for the physical IPV outcome measure, consisting of 12 items representing minor and severe physical assault subscales, was $[\alpha]=.86$ for the entire sample, $[\alpha]=.87$ for males and $[\alpha]=.87$ for female participants.

\section{Correlations}

In an effort to assess the efficacy of the scaled measures simple zero-order correlations were conducted. These bivariate statistics helped to establish the relative importance of these measures in testing the study hypotheses (see Table 4.4). The correlations that are of note consisted of each of the scaled measures with the outcome measure of physical IPV. As suspected, the differentiation of self was significantly related to relationship satisfaction $(r=$ $.239, p<.01)$, and negatively correlated to marital conflict $(r=-.297, p<.01)$, depression $(r=-$ $.201, p<.01)$, anxiety $(r=-.229, p<.01)$ and the outcome measure intimate partner violence $(r$ $=-.206, p<.01)$. Depression and Anxiety were also shown to be strongly and negatively correlated with relationship satisfaction. That trend among these two variables continued with positive correlations with romantic jealousy and a very strong connection between depression and anxiety $(r=.690, p<.001)$. As far as the outcome measure, romantic jealousy $(r=.226, p$ 
$<.01)$, depression $(r=.273, p<.01)$, and anxiety $(r=.226, p<.01)$ were all found to be significant. Ironically, attitude toward violence was not significantly correlated to any of the study measures.

Table 4.4.

Zero Order Correlation Coefficients for Selected Domains of the Differentiation in IPV Model with IPV.

\begin{tabular}{|c|c|c|c|c|c|c|c|c|}
\hline & 1 & 2 & 3 & 4 & 5 & 6 & 7 & 8 \\
\hline $\begin{array}{l}\text { (1) Differentiation of } \\
\text { Self }\end{array}$ & 1 & & & & & & & \\
\hline $\begin{array}{l}\text { (2) Relationship } \\
\text { Satisfaction }\end{array}$ & $.239 * *$ & 1 & & & & & & \\
\hline (3) Marital Conflict & $-.297 * *$ & $-.397 * *$ & 1 & & & & & \\
\hline $\begin{array}{l}\text { (4) Romantic } \\
\text { Jealousy }\end{array}$ & -.121 & .072 & .037 & 1 & & & & \\
\hline (5) Depression & $-.201 * *$ & $-.389 * *$ & $.229 * *$ & $.268 * *$ & 1 & & & \\
\hline (6) Anxiety & $-.229 * *$ & $-.177 * *$ & $.158 * *$ & $.311 * *$ & $.690 * *$ & 1 & & \\
\hline $\begin{array}{l}\text { (7) Attitude Toward } \\
\text { Violence }\end{array}$ & -.050 & .084 & -.013 & .069 & -.054 & -.004 & 1 & \\
\hline (8) IPV & $-.206 * *$ & .002 & .005 & $.226 * *$ & $.273 * *$ & $.226^{* *}$ & .086 & 1 \\
\hline
\end{tabular}

Overall the results indicated that the only variable that is not significantly correlated to the rest of the study variables was Attitude Toward Violence. As a result, this measure was dropped from subsequent analyses. The other finding was related to the correlations between predictor variables and the outcome (physical IPV). Marital satisfaction and marital conflict, though considered as risk factors for physical IPV in the professional literature, were not found to be significantly correlated with physical IPV as defined in this study—presence and level of severity of physical assault. However, they were included in subsequent tests because of their significant correlations with differentiation of self. Correlation analyses were also conducted for each gender group. Results are presented in Tables 4.5 and 4.6 for each gender separately. 
Table 4.5.

Zero Order Correlation Coefficients for Selected Domains of the Differentiation in IPV Model with IPV for Males.

\begin{tabular}{|c|c|c|c|c|c|c|c|c|}
\hline & 1 & 2 & 3 & 4 & 5 & 6 & 7 & 8 \\
\hline $\begin{array}{l}\text { (1) Differentiation of } \\
\text { Self }\end{array}$ & 1 & & & & & & & \\
\hline $\begin{array}{l}\text { (2) Relationship } \\
\text { Satisfaction }\end{array}$ & $.241 * *$ & 1 & & & & & & \\
\hline (3) Marital Conflict & $-.322 * *$ & $-.362 * *$ & 1 & & & & & \\
\hline $\begin{array}{l}\text { (4) Romantic } \\
\text { Jealousy }\end{array}$ & $-.178 *$ & .118 & .048 & 1 & & & & \\
\hline (5) Depression & $-.327 * *$ & $-.420 * *$ & $.190 *$ & $.188^{*}$ & 1 & & & \\
\hline (6) Anxiety & $-.297 * *$ & $-.175^{*}$ & .118 & $.215^{* *}$ & $.645 * *$ & 1 & & \\
\hline $\begin{array}{l}\text { (7) Attitude Toward } \\
\text { Violence }\end{array}$ & -.050 & .079 & .027 & .130 & -.063 & -.006 & 1 & \\
\hline (8) IPV & $-.228 * *$ & -.020 & -.079 & $.234 * *$ & $.259 * *$ & $.237 * *$ & $.174 *$ & 1 \\
\hline
\end{tabular}

$* \mathrm{p}<.05 .{ }^{* *} \mathrm{p}<.01$ (2-tailed).

Table 4.6.

Zero Order Correlation Coefficients for Selected Domains of the Differentiation in IPV Model with IPV for Females.

\begin{tabular}{|c|c|c|c|c|c|c|c|c|}
\hline & 1 & 2 & 3 & 4 & 5 & 6 & 7 & 8 \\
\hline $\begin{array}{l}\text { (1) Differentiation of } \\
\text { Self }\end{array}$ & 1 & & & & & & & \\
\hline $\begin{array}{l}\text { (2) Relationship } \\
\text { Satisfaction }\end{array}$ & $.216^{*}$ & 1 & & & & & & \\
\hline (3) Marital Conflict & $-.244 * *$ & $-.374 * *$ & 1 & & & & & \\
\hline $\begin{array}{l}\text { (4) Romantic } \\
\text { Jealousy }\end{array}$ & -.038 & .094 & .109 & 1 & & & & \\
\hline (5) Depression & -.024 & $-.283 * *$ & $.216^{*}$ & $.330 * *$ & 1 & & & \\
\hline (6) Anxiety & -.132 & -.130 & .171 & $.399 * *$ & $.734 * *$ & 1 & & \\
\hline $\begin{array}{l}\text { (7) Attitude Toward } \\
\text { Violence }\end{array}$ & .026 & .019 & -.042 & .019 & -.016 & .016 & 1 & \\
\hline (8) IPV & -.184 & .029 & .189 & $.218^{*}$ & $.297 * *$ & $.215^{*}$ & -.025 & 1 \\
\hline
\end{tabular}

$* \mathrm{p}<.05 . * * \mathrm{p}<.01$ (2-tailed). 
The results reveal that the intimate partner violence is negatively correlated with differentiation of self $(r=-.288, p<.01)$ for males but that it was not for females. In terms of relationship satisfaction and marital conflict there were no significant findings for either group. It does appear that romantic jealousy did play a role in physical IPV, with both males $(r=.234, p<$ $.01)$ and females $(r=.218, p<.05)$ revealing significant scores. The trend continues, respectively, for depression $(r=.259, p<.01)(r=.295, p<.01)$, anxiety $(r=.237, p<.01)(r=$ $.215, p<.05)$ and attitude toward violence for males $(r=.174, p<.05)$ but not females. It is clear that for both sexes depression and anxiety were also strongly and significantly correlated as revealed in Tables 4.5 and 4.6.

In general, the results of zero-order correlation tests for each gender group revealed some interesting findings. For male participants, differentiation of self was significantly related with all the other study variables except for the attitude towards violence. However, for females, differentiation of self was significantly related to relationship satisfaction and marital conflict only, but not to romantic jealousy, depression, anxiety, attitude towards violence, and physical IPV. These findings and their implications are further discussed in the Chapter Five.

\section{Results for Hypotheses Tests}

The following section presents results of hypotheses tests that were developed in conjunction with the Differentiation of Self and Intimate Partner Violence model. Each hypothesis examines a specific aspect of the model and helps to explicate the overall utility of the model.

\section{Hypothesis 1}

The first hypothesis examines whether differentiation of self will have a significant effect on physical IPV independent of the risk factors of depression and anxiety. This hypothesis was 
tested using Hierarchical Regression Analysis. Known predictors from research are entered first into the model followed by any new predictors to be tested. In this study, the known risk factors included in this hypothesis, depression and anxiety were entered in the first block of predictor variables. Differentiation of self was entered in the second block in order to test for additional variance on physical IPV accounted for by this variable above and beyond the variance accounted for by depression and anxiety.

Table 4.7

Hierarchical Regression Analyses for Influence of Differentiation in IPV Model Predicting IPV from Model Components Depression, Anxiety, and Differentiation for Hypothesis One.

\begin{tabular}{|c|c|c|c|c|c|}
\hline Model & $B$ & $S E$ & $\beta$ & $R_{a d j}^{2}$ & $\Delta R^{2}$ \\
\hline \multicolumn{6}{|l|}{ Block $1^{a}$} \\
\hline Depression & 0.09 & 0.04 & $0.17 *$ & 0.09 & 0.09 \\
\hline Anxiety & 0.07 & 0.04 & $0.15 * *$ & & \\
\hline \multicolumn{6}{|l|}{ Block $2^{b}$} \\
\hline Depression & 0.08 & 0.04 & 0.16 & 0.11 & $0.02 *$ \\
\hline Anxiety & 0.06 & 0.04 & 0.12 & & \\
\hline Differentiation & -0.13 & 0.06 & $-0.15^{*}$ & & \\
\hline
\end{tabular}

${ }^{\mathrm{a}}$ Predictors: (Constant), Depression, and Anxiety.

'Predictors: (Constant), Depression, Anxiety, and Differentiation.

The results of the Hierarchical Regression Analysis revealed that the three factors (anxiety, depression, and differentiation of self) are significant predictors of physical IPV. Table 4.7 shows the values of coefficients for independent variables included at each step of the procedure along with their significance. Results of Step 1 of the Hierarchical Regression procedure showed that anxiety and depression together explain a significant portion of variance in physical IPV, $R^{2}=.09$ or $9 \%$ of the variance $\left(F_{(2,234)}=11.03, p<.001\right)$. The contribution of differentiation of self was assessed in Step 2. Results showed that inclusion of differentiation of self significantly increased the portion of explained variance in physical IPV, $R^{2}$ change $=.02$, $\left(F_{(1,233)}=5.57, p<.05\right)$. Together these two steps produced an $R^{2}$ of .11 $\left(F_{(3,233)}=9.36, p<.001\right)$ 
accounting for $11 \%$ of variance in physical IPV. These results indicate that the lower the level of differentiation of self, the higher the incidence of perpetration of physical IPV (negative beta coefficient for differentiation) revealing that this hypothesis was supported.

In addition to conducting the Hierarchical Regression test for the entire sample, I ran the same regression for each gender group. Table 4.8 and 4.9 display results of these tests for males and females. Contrary to the results for the entire sample, for each of the groups, differentiation of self, did not contribute to the explained variance in physical IPV after anxiety and depression were entered into the model. In fact, the $R^{2}$ Change accounted for only $2 \%$ and $3 \%$ change for males and females respectively, none of the models were significantly improved (for males $R^{2}$ change $=.02, F_{(1,136)}=2.61, p>.05$; and for females $R^{2}$ change $\left.=.03, F_{(1,93)}=3.21, p>.05\right)$. Therefore, there were no quantifiable gender differences in terms of depression, anxiety, and differentiation and intimate partner violence as revealed by the current models.

Table 4.8

Hierarchical Regression Analyses for Influence of Differentiation in IPV Model Predicting IPV from Model Components Depression, Anxiety, and Differentiation for Hypothesis One Controlling for Males.

\begin{tabular}{|c|c|c|c|c|c|}
\hline Model & $B$ & $S E$ & $\beta$ & $R_{a d j}^{2}$ & $\Delta R^{2}$ \\
\hline \multicolumn{6}{|l|}{ Block $1^{a}$} \\
\hline Depression & 0.09 & 0.06 & 0.16 & 0.09 & 0.09 \\
\hline Anxiety & 0.09 & 0.06 & 0.16 & & \\
\hline \multicolumn{6}{|l|}{ Block $2^{b}$} \\
\hline Depression & 0.07 & 0.06 & 0.13 & 0.10 & $0.01 *$ \\
\hline Anxiety & 0.08 & 0.06 & 0.14 & & \\
\hline Differentiation & -0.14 & 0.08 & -0.14 & & \\
\hline
\end{tabular}

$* * *=p<.001, * *=p<.01, *=p<.05$.

âredictors: (Constant), Depression, and Anxiety.

${ }^{\mathrm{b}}$ Predictors: (Constant), Depression, Anxiety, and Differentiation. 
Table 4.9

Hierarchical Regression Analyses for Influence of Differentiation in IPV Model Predicting IPV from Model Components Depression, Anxiety, and Differentiation for Hypothesis One Controlling for Females.

\begin{tabular}{|c|c|c|c|c|c|}
\hline Model & $B$ & $S E$ & $\beta$ & $R_{a d j}^{2}$ & $\Delta R^{2}$ \\
\hline \multicolumn{6}{|l|}{ Block $1^{a}$} \\
\hline Depression & 0.10 & 0.07 & 0.23 & 0.10 & 0.10 \\
\hline Anxiety & 0.05 & 0.08 & 0.11 & & \\
\hline \multicolumn{6}{|l|}{ Block $2^{b}$} \\
\hline Depression & 0.11 & 0.07 & 0.24 & 0.13 & $0.03 * *$ \\
\hline Anxiety & 0.03 & 0.06 & 0.07 & & \\
\hline Differentiation & -0.13 & 0.07 & -0.18 & & \\
\hline
\end{tabular}

\section{Hypothesis 2}

The second hypothesis examined whether differentiation has a significant effect on physical IPV independent of the risk factors of relationship satisfaction, marital conflict and romantic jealousy. This hypothesis was tested using Hierarchical Regression Analysis.

Relationship satisfaction, marital conflict and romantic jealousy were entered first into the model followed by differentiation of self entered in the second block. This test explores the additional variance of differentiation of self on perpetration of physical IPV above and beyond the variance accounted for by relationship satisfaction, marital conflict and romantic jealousy.

The results of the Hierarchical Regression Analysis indicated that the four factors (relationship satisfaction, marital conflict, romantic jealousy and differentiation of self) are significant predictors of physical IPV $\left.F_{(4,230)}=5.54, p<.001\right)$ accounting for $9 \%$ of variance in perpetration of physical IPV. Table 4.10 shows the values of coefficients for independent variables included at each step of the procedure along with their significance. Results of Step 1 of the Hierarchical Regression Analysis showed that relationship satisfaction, marital conflict 
and romantic jealousy together explain a significant portion of variance in perpetration of physical IPV, $\left.F_{(3,231)}=3.44, p<.05\right)$. However, out of the three variables, romantic jealousy was the only one that significantly predicted variance in the dependent variable physical IPV. The contribution of differentiation of self was assessed in Step 2. Results showed that inclusion of differentiation of self significantly increased the portion of explained variance in perpetration of physical IPV,$R^{2}$ change $\left.=0.05, F_{(1,230)}=11.36, p<.01\right)$, accounting for an additional $5 \%$ of the variance in physical IPV perpetration.

Table 4.10

Hierarchical Regression Analyses for Influence of Differentiation in IPV Model Predicting IPV from Model Components Depression, Anxiety, and Differentiation for Hypothesis Two.

\begin{tabular}{lccccc}
\hline \multicolumn{1}{c}{ Model } & $B$ & $S E$ & $\beta$ & $R^{2}{ }_{a d j}$ & $\Delta R^{2}$ \\
\hline Block $^{a}$ & & & & & \\
Relationship Satisfaction & 0.01 & 0.02 & 0.04 & 0.04 & 0.04 \\
Marital Conflict & 0.00 & 0.04 & 0.00 & & \\
Romantic Jealousy & 0.11 & 0.04 & $0.20^{* *}$ & & \\
& & & & & \\
Block2 $^{b}$ & & & & & \multirow{2}{*}{$0.05^{* *}$} \\
Relationship Satisfaction & 0.02 & 0.02 & 0.08 & 0.09 & \\
Marital Conflict & -0.03 & 0.04 & -0.05 & & \\
Romantic Jealousy & 0.10 & 0.04 & $0.18^{* *}$ & & \\
Differentiation & -0.21 & 0.06 & $-0.23^{* *}$ & & \\
\hline
\end{tabular}

$* * *=p<.001, * *=p<.01, *=p<.05$.

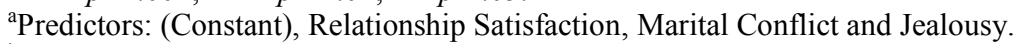

${ }^{b}$ Predictors: (Constant), Relationship Satisfaction, Marital Conflict, Jealousy, and Differentiation.

Hypothesis 2 was supported. Differentiation of self is a significant predictor of physical IPV perpetration above and beyond relationship satisfaction, marital conflict and romantic jealousy combined. In step 2, differentiation of self was the strongest predictor of physical IPV, $\beta=-0.23$. These results indicate that the lower the level of self differentiation and the higher the jealousy, the higher the incidence of perpetration of physical IPV (negative coefficient for differentiation and a positive coefficient for jealousy). 
Table 4.11

Hierarchical Regression Analyses for Influence of Differentiation in IPV Model Predicting IPV from Model Components Depression, Anxiety, and Differentiation for Hypothesis Two

Controlling for Males.

\begin{tabular}{|c|c|c|c|c|c|}
\hline Model & $B$ & $S E$ & $\beta$ & $R_{a d j}^{2}$ & $\Delta R^{2}$ \\
\hline \multicolumn{6}{|l|}{ Block $^{a}$} \\
\hline Relationship Satisfaction & -0.01 & 0.03 & -0.04 & 0.04 & 0.04 \\
\hline Marital Conflict & -0.05 & 0.05 & -0.08 & & \\
\hline Romantic Jealousy & 0.11 & 0.05 & $0.18^{*}$ & & \\
\hline \multicolumn{6}{|l|}{ Block $2^{b}$} \\
\hline Relationship Satisfaction & 0.01 & 0.03 & 0.02 & 0.09 & $0.05 * *$ \\
\hline Marital Conflict & -0.09 & 0.05 & -0.16 & & \\
\hline Romantic Jealousy & 0.07 & 0.06 & 0.11 & & \\
\hline Differentiation & -0.27 & 0.10 & $-0.26 * *$ & & \\
\hline
\end{tabular}

Table 4.12

Hierarchical Regression Analyses for Influence of Differentiation in IPV Model Predicting IPV from Model Components Depression, Anxiety, and Differentiation for Hypothesis Two Controlling for Females.

\begin{tabular}{lccccc}
\hline \multicolumn{1}{c}{ Model } & $B$ & $S E$ & $\beta$ & $R_{\text {adj }}^{2}$ & $\Delta R^{2}$ \\
\hline Block1 $^{a}$ & & & & & \\
Relationship Satisfaction & 0.04 & 0.03 & 0.15 & 0.11 & 0.11 \\
Marital Conflict & 0.11 & 0.06 & 0.20 & & \\
Romantic Jealousy & 0.10 & 0.05 & $0.22^{*}$ & & \\
& & & & & \\
Block2 $^{b}$ & & & & $0.04^{*}$ \\
Relationship Satisfaction & 0.06 & 0.03 & 0.20 & 0.15 & \\
Marital Conflict & 0.09 & 0.06 & 0.16 & & \\
Romantic Jealousy & 0.11 & 0.05 & $0.22^{*}$ & & \\
Differentiation & -0.16 & 0.08 & $-0.21^{*}$ & & \\
\hline
\end{tabular}

$* * *=p<.001, * *=p<.01, *=p<.05$.

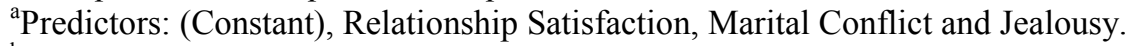

${ }^{b}$ Predictors: (Constant), Relationship Satisfaction, Marital Conflict, Jealousy, and Differentiation. 
Similarly to Hypothesis 1 testing, I ran the Hierarchical Regression test for each gender group.

Tables 4.11 and 4.12 display results of these tests for males and females respectively. Results of the test for each group are similar to those for the entire sample. For each of the groups individually, differentiation of self added to the explained variance in physical IPV after relationship satisfaction, marital conflict and romantic jealousy were entered into the model (for males: $R^{2}$ change $=.54, F_{(1,136)}=8.04, p<.01$; and for females: $R^{2}$ change $=.04, F_{(1,89)}=4.32, p$ $<.05)$.

\section{Hypothesis 3}

The third hypothesis examined whether there are gender differences in the level of physical IPV, differentiation of self, and other known risk factors including relational satisfaction, marital conflict, romantic jealousy, depression, and anxiety. Independent samples ttests were conducted. Results of these tests are presented in Table 4.13.

Table 4.13

Results of Differences of Means Testing by Gender for the Differentiation in IPV Model Study Variables.

\begin{tabular}{llrrc}
\hline Variable & Gender & $n$ & Mean & \multicolumn{1}{c}{$t$} \\
\hline \multirow{2}{*}{ Differentiation of Self } & Male & 159 & 3.78 & 1.39 \\
& Female & 111 & 3.70 & \\
Relationship Satisfaction & Male & 184 & 4.37 & $4.90^{* * *}$ \\
& Female & 135 & 3.52 & \\
Marital Conflict & Male & 155 & 2.93 & $-3.60^{* * *}$ \\
& Female & 116 & 3.30 & \\
Romantic Jealousy & Male & 177 & -0.08 & $-2.17^{*}$ \\
\multirow{2}{*}{ Depression } & Female & 130 & 0.12 & \\
\multirow{2}{*}{ Anxiety } & Male & 172 & 1.23 & $-3.14^{* *}$ \\
\multirow{2}{*}{ IPV } & Female & 131 & 1.56 & \\
& Male & 179 & 0.68 & $-2.14^{*}$ \\
\hline
\end{tabular}

$* * *=p<.001, * *=p \quad<.01, *=p<.05$.

As shown in Table 4.13, gender differences were observed for several of the study variables. Relationship satisfaction is significantly higher for males $(M=4.37)$ compared to 
females $(M=3.52)(t=4.90, p<.001)$. On the other hand, female participants in this study reported significantly higher levels of marital conflict $(M=3.30)$ compared to male participants $(M=2.93)(t=-3.60, p<001)$. Significant differences were also observed regarding romantic jealousy where females $(M=0.12)$ reported significantly higher levels of romantic jealousy compared to males $(M=-0.08)(t=-2.17, p=.05)$.

Depression $(t=-3.14, p<.01)$ and anxiety $(t=-2.14, p<.05)$ were also significantly higher for females compared to males. However, no significant gender differences were observed regarding the two main constructs of this study—differentiation of self and physical IPV. These gender differences among all the other risk factors reinforce the need for further exploration of the role of gender in the context of the relationship between differentiation of self and physical IPV. We can conclude that this hypothesis was partially supported. Gender differences were observed for the known risk factors, but not for physical IPV and differentiation of self.

\section{Hypothesis 4}

In order to test Hypothesis 4 whether gender impacts the relationship between self differentiation and other risk factors (depression, anxiety, marital satisfaction, marital conflict, and jealousy) on perpetration of physical IPV, subjects were classified into groups based on their level of differentiation of self. The TwoStep Cluster Analysis procedure in SPSS was used to group the study participants based on their level of differentiation of self. This procedure can be used as an exploratory tool to reveal natural groupings within the data set. As such, the statistical method determines the optimal number of groups instead of the researcher specifying or forcing the number of clusters. This approach was followed in this study.

This classification was done for two reasons: a) gender is a categorical variable and differentiation of self is a continuous variable, thus by creating groups it is easier to conduct 
Analysis of Variance (ANOVA) to explore the role of gender in the relationship between differentiation of self and physical IPV; b) by creating groups based on levels of differentiation of self we can gain more insights how the different levels of differentiation of self are related to perpetration of physical IPV.

The results of the cluster analysis are shown in Table 4.14. As shown, this analysis revealed three groups based on their levels of differentiation of self. Based on the group means, participants classified in the first group $($ Mean=3.24) were considered with lower level of differentiation of self. Participants in the second group (Mean=3.88) were considered with a moderate level of differentiation of self, and those in the third group (Mean=4.50) were considered with a higher level of differentiation of self.

Table 4.14

Distribution of Participants by Differentiation of Self Groupings for Cluster Analysis of Differentiation in IPV Model.

\begin{tabular}{lccc}
\hline \multicolumn{1}{c}{ Group } & $n$ & \% of Total & Mean \\
\hline 1 [Low Differentiation] & 105 & 38.9 & 3.24 \\
2 [Moderate Differentiation] & 116 & 43.0 & 3.88 \\
3 [High Differentiation] & 49 & 18.1 & 4.50 \\
\hline
\end{tabular}

To test the moderating role of gender, data were analyzed using Analyses of Covariance (ANCOVA), an extension of ANOVA, which allows the inclusion of control variables and adjustments for the differences in covariates. Such factors in this study are all other known risk factors: depression; anxiety; marital satisfaction; marital conflict; and jealousy. The results of the Descriptive statistics derived for use in the ANCOVA test are described in Table 4.15.

The results of ANCOVA showed that the level of differentiation of self had an overall effect on physical IPV, $F_{(2,222)}=3.53, p<.05$. This means that the population means of the 
criterion (physical IPV) were significantly different between the groups of the levels of differentiation of self. However, the result of ANCOVA showed no significant main effect for gender $F_{(1,223)}=0.02, p>.05$. In addition, the interaction effect between gender and levels of differentiation of self was not significant $F_{(2,222)}=0.58, p<.05$ indicating that there was no effect of gender as was revealed in the zero order correlations where non-significant coefficient were generated. Table 4.16 shows the results of ANCOVA for all variables.

Table 4.15

Means and Standard Deviations of Distribution of Participants by Differentiation of Self Groupings by Gender Using Clustering Effect for ANCOVA Analysis of the Differentiation in IPV Model.

\begin{tabular}{|c|c|c|c|}
\hline Group and Type Measures & $n$ & Mean & StdDev \\
\hline \multicolumn{4}{|l|}{ Male } \\
\hline Low & 53 & 0.43 & 0.44 \\
\hline Moderate & 59 & 0.40 & 0.55 \\
\hline High & 21 & 0.13 & 0.17 \\
\hline \multicolumn{4}{|l|}{ Female } \\
\hline Low & 37 & 0.44 & 0.45 \\
\hline Moderate & 36 & 0.30 & 0.39 \\
\hline High & 18 & 0.25 & 0.34 \\
\hline
\end{tabular}

Note: Dependent Variable is IPV.

Table 4.16

Factorial ANCOVA Results for Influence of Differentiation and Gender in IPV

\begin{tabular}{lrrrl}
\hline \multicolumn{1}{c}{ Source } & $\begin{array}{c}\text { Sums of } \\
\text { Squares }\end{array}$ & $d f$ & Mean Square & $F$ \\
\hline Corrected Model & 6.394 & 10 & 0.639 & $3.520^{* * *}$ \\
Intercept & 0.020 & 1 & 0.020 & 0.113 \\
Relationship Satisfaction & 0.673 & 1 & 0.673 & 3.703 \\
Marital Conflict & 0.660 & 1 & 0.660 & 0.418 \\
Romantic Jealousy & 0.134 & 1 & 0.137 & 0.739 \\
Depression & 1.143 & 1 & 1.143 & $6.296^{* *}$ \\
Anxiety & 0.196 & 1 & 0.196 & 1.080 \\
Gender & 0.003 & 1 & 0.003 & 0.989 \\
Differentiation & 1.281 & 2 & 0.641 & $3.528^{*}$ \\
Gender* Differentiation & 443.326 & 2 & 15.883 & 1.445 \\
Error & 38.683 & 213 & 10.955 & \\
Total & 74.361 & 224 & & \\
\hline
\end{tabular}

$* * * p<.001 . * * p<.01 . * p<.05$. 
Since differentiation of self is significantly related to physical IPV, a follow-up analysis was conducted to examine which groups differ with regard to physical IPV. Post-hoc testing using the Bonferroni pairwise comparison procedure uncovered a significant difference between the groups with the lowest and highest levels of differentiation of self (mean difference $=0.24, p$ $<.05)$. This finding indicates that perpetration of physical IPV for the group with the low level of differentiation of self was significantly higher than the group with the highest level of differentiation of self.

However, there were no significant differences in perpetration of physical IPV between groups with moderate and high levels differentiation of self, and moderate and low. To conclude, Hypothesis 4 was supported. It appears that Gender does not directly affect perpetration of physical IPV and it does not have an impact on the relationship between differentiation of self and physical IPV as was hypothesized. 


\section{CHAPTER FIVE \\ DISCUSSION AND CONCLUSIONS}

\section{Overview}

This chapter discusses the findings and the conclusions that can be drawn from this study. Differentiation of self has been indicated in previous research to be related to physical IPV, yet little research exists to analyze empirically the relationships between differentiation of self, physical IPV and other known risk factors for physical IPV. The purpose of this study was to examine the role of differentiation of self in a relationship on physical IPV. Four hypotheses were proposed based on the literature on differentiation and physical IPV. The following discusses the results of hypotheses testing, implications for research and practice, future directions for research and limitations of this study.

\section{Summary and Discussion}

Most of the studies on IPV have examined risk factors for physical IPV such as relational satisfaction and marital conflict (Cano \& Vivian, 2003; Lawrence \& Bradbury, 2001; Panuzio \& DiLillo, 2010; Schumacher \& Leonard, 2005; Stith et al., 2008; Stith at al., 2004b), romantic jealousy (Babcock, Costa, \& Green, 2004; Barnett, Martinez, \& Bluestein, 1995; Hannawa, Spitzberg, Wiering, \& Teranishi, 2006; Wilson \& Daly, 1998; 2001), and depression and anxiety (Boyle \& Vivian, 1996; Maiuro et al., 1988; Pan et al., 1994; Vivian \& Malone 1997). However, little research existed on the relationship of differentiation of self and physical IPV.

The first hypothesis tested whether differentiation of self would have a significant effect on physical IPV independent of the risk factors of depression and anxiety. This hypothesis was supported. The lower the level of differentiation of self, the higher was the level of perpetration of physical IPV for the entire sample. Differentiation of self plays a significant role in 
perpetration of physical IPV, independent of depression and anxiety. Although both depression and anxiety were significantly correlated with physical IPV in the univariate correlation analysis, when both factors were entered into a regression analysis predicting physical IPV, only depression significantly predicted physical IPV in this study. This means the higher the depression, the higher the level of perpetration of physical IPV. However, when differentiation of self was added as an additional factor in step two of the hierarchical regression analysis, depression and anxiety were not significant predictors of physical IPV, but differentiation of self was found to predict perpetration of physical IPV. This could be an indication of a greater relative importance of differentiation of self compared to these factors in the explanation of physical IPV, and/or indicative of two or more possible relationships between depression, differentiation, and physical IPV. We know from previous research that lower levels of differentiation of self are associated with depression and other mood disorders (Elieson \& Rubin, 2001), differentiation is a predictor of mood disorders and psychological distress (Johnson \& Buboltz, 2000; Murdock \& Gore, 2004), and that depression is a predictor of IPV (Boyle \& Vivian, 1996; Vivian \& Malone, 1997). Correlation analyses in this study also supports findings of past research indicating that differentiation of self was negatively related to depression and anxiety. However, when entered into a multivariate analysis, differentiation of self seems to be a stronger predictor of physical IPV compared to depression and anxiety. There is clearly a need for future research to further investigate the relationships between mood disorders, differentiation and physical IPV.

When hypothesis one was tested for each gender group separately, the level of differentiation of self did not add significantly to the level of prediction of physical IPV that anxiety and depression already provided. The fact that results of the test by group differed from 
the results for the entire sample may be explained by the reduced sample size for group level analysis. It may also be an indication that gender might not play any role in the relationship between differentiation of self and physical IPV. Therefore this finding remains an issue that deserves further exploration in future research.

The second hypothesis examined whether differentiation of self would have a significant effect on physical IPV independent of the risk factors of relationship satisfaction, marital conflict and romantic jealousy. I wanted to assess the degree to which differentiation of self adds to the prediction of perpetration of physical IPV above and beyond these known relational risk factors. This hypothesis was supported. Differentiation of self plays a significant role in the perpetration of physical IPV, independent of relationship satisfaction, marital conflict and romantic jealousy. Preliminary correlation analyses indicated that differentiation of self and relationship satisfaction and marital conflict were significantly correlated. However, differentiation of self was not related to jealousy in the univariate analysis. The current multivariate analysis showed that relationship satisfaction and marital conflict were not predictors of physical IPV in the model before or after differentiation of self was included. On the other hand, jealousy was the only factor in this group that was significantly related to physical IPV both before and after inclusion of differentiation of self. Considering these relationships between these factors and differentiation of self, there may be indications that relationship satisfaction and marital conflict may not be direct predictors of physical IPV but may be indirectly related to physical IPV through differentiation of self. The fact that jealousy is not related to differentiation of self shows that this risk factor is an independent predictor of physical IPV. To conclude, this study showed that individuals with lower levels of differentiation of self in a relationship and higher levels of jealousy perpetrate physical IPV at higher incidence levels. 
The fact that jealousy and differentiation of self were found to be predictors of IPV is in agreement with previous research findings. Previous research has consistently found jealousy to be significantly related to IPV (Babcock et al., 2004; Barnett et al., 1995; Dutton, van Ginkel, \& Landolt, 1996; Fenton \& Rathus, 2010; Puente \& Cohen, 2003; Sugarman \& Hotaling, 1989; Wilson \& Daly, 1998). The predictive strength of jealousy was supported in this research, even when differentiation of self was added to the analysis. Previous research has examined the role of jealousy and differentiation on physical IPV, and has shown that differentiation and jealousy have an impact on physical IPV (Glickauf-Hughes et al., 1998; Schubert et al., 2002). This study provides more evidence for jealousy and differentiation of self as predictors of physical IPV.

Similar to $\mathrm{H1}$, the predictive role of differentiation of self relative to relationship satisfaction, marital conflict and romantic jealousy was examined for each gender group. For both gender groups findings were the same as for the entire sample: differentiation of self had an additional effect on prediction of physical IPV. Differences were noted between genders when differentiation of self was added as an additional factor. For males, differentiation of self was the only predictor for physical IPV. For females, findings were similar to the entire sample where both differentiation of self and jealousy were predictors of perpetration of physical IPV. A possible explanation for these differences can be explained by the differences in the relationship between romantic jealousy and differentiation of self for males and females. Correlation analysis showed that for females differentiation of self is not related to jealousy, but for males this relationship exists.

Hypotheses one and two provided support that differentiation of self plays a significant role in explaining perpetration of physical IPV for both males and females. Both hypotheses aimed at isolating the additional effect of differentiation of self on physical IPV above and 
beyond other known risk factors. Since both these two hypotheses were supported we can conclude that differentiation of self is another predictor for perpetration of physical IPV. These findings inform us that an individual's level of differentiation of self in a relationship impacts their level of violence. Thus, differentiation of self necessitates attention from researchers evaluating prevention and treatment programs as well as from clinicians in assessing levels of differentiation and targeting treatment efforts to enhance levels of differentiation.

The third hypothesis examined gender differences between males and females on their levels of perpetration of physical IPV, differentiation of self, and other risk factors including depression, anxiety, marital satisfaction, marital conflict, and romantic jealousy. Previous studies have indicated that both males and females are perpetrators and victims of physical IPV, although most research suggests that males perpetrate higher rates of violence and use more severe levels of violence than females (Archer, 2000; Black et al., 2011).

With regard to the known risk factors, gender differences were observed between males and females in this study for all factors. Specifically, females in this sample reported lower relationship satisfaction than their male counterparts. Females also reported a greater level of marital conflict and higher levels of jealousy than males. Regarding mental health factors in this study, females reported higher levels of depression and anxiety than males. These results may indicate actual differences in perceptions and experiences related to these factors, or it can be that men provide more socially desirable answers than females.

Regarding the two main study variables, differentiation of self and physical IPV, there were no gender differences between males and females. These findings showed that although males and females in this study are different with regard to all other known risk factors, they report similar levels of differentiation of self and levels of perpetration of physical IPV. This is 
consistent with findings from previous research on physical IPV perpetration that has shown that both males and females perpetrate physical IPV. In terms of differentiation of self, gender differences have not been researched adequately, and Bowen's theory posits that no gender differences exist on levels of differentiation (Bowen, 1978). Findings in this study support Bowen theory and provide some initial support for the idea that there may not be gender differences regarding differentiation of self.

Another way to look at gender differences is to analyze how risk factors, including differentiation of self, are related to each other for each gender group. Correlation analysis revealed the following. For males, differentiation of self was positively correlated with relationship satisfaction and it was negatively related to marital conflict, romantic jealousy, depression, and anxiety. This means the more satisfied male participants were with their relationship, the higher the level of differentiation they reported. On the other hand, the higher the marital conflict, jealousy, depression and anxiety, the lower was the level of differentiation of self. However, for females differentiation of self was significantly related only to relationship satisfaction and marital conflict. This means that the more satisfied female participants were with their relationship and the less marital conflict present, the higher the level of differentiation they reported.

The purpose of the fourth hypothesis was two-fold. First, I wanted to examine the role of gender on physical IPV when controlling for the known risk factors, and second, I wanted to analyze the role of gender in the relationship between differentiation of self and physical IPV. This study showed that gender did not have a significant effect on the level of perpetration of physical IPV when controlling for the known risk factors. This is consistent with the findings from the previous hypothesis that showed that males and females did not differ in their level of 
physical IPV without considering any risk factor. The results of this hypothesis provide further support that males and females in this data set perpetrate violence at similar levels of severity.

This study also showed that gender does not moderate the relationship between differentiation of self and perpetration of physical IPV. This means that differentiation of self effects IPV the same for males and females. For both males and females, the lower the level of differentiation of self, the higher the level of perpetration of physical IPV.

The testing of hypothesis four provided additional support for the first and second hypothesis on the role of differentiation of self as a predictor for physical IPV. When controlling for all known risk factors at the same time, differentiation of self was found to be a significant predictor of perpetration of physical IPV. In order to better understand the relationship between differentiation of self and physical IPV, statistical analyses were conducted to classify study participants into groups based on their level of differentiation. The data used in this study revealed that the participants in this study could be grouped into three categories on their level of differentiation of self, labeled as low, moderate, and high. Further analysis showed that only

groups with low and high levels of differentiation differed in their level of perpetration of physical IPV. The lower the level of differentiation of self, the higher the level of perpetration of physical IPV.

\section{Implications for Research and Practice of Marriage and Family Therapy}

The findings of this study add to the literature on the role of differentiation of self on perpetration of physical IPV for males and females. Findings were generally consistent with previous research that had indicated a relationship between differentiation and physical IPV, and they inform research and practice on differentiation of self being a predictor for physical IPV. However, the relationship of differentiation of self with other known risk factors that were 
included in this study indicate a need for future research to better understand their interaction with one another, their relationship to differentiation of self and physical IPV, and impact on physical IPV. For example, this study supported past research that mood disorders can explain a portion of the variance for physical IPV, but when differentiation of self was added to the model, depression and anxiety were not significant predictors of physical IPV for the entire sample. Questions were raised regarding the relationship between depression and anxiety and differentiation of self and their effect on physical IPV, clearly indicating a need to further investigate these relationships. Additionally, research on the relationship between romantic jealousy and differentiation of self is scarce, but the existing research and this study provided evidence that both these factors are individually and together predictors of physical IPV.

Our findings on the role of gender on differentiation of self and IPV added to the literature and provided support for Bowen's theory on gender and differentiation. This study showed that gender does not moderate the relationship between differentiation of self and perpetration of physical IPV. However, this study also showed significant gender differences among all the risk factors in this study, reinforcing the need for further exploration of the role of gender in physical IPV.

Future research should examine the relationships that may exist between all risk factors and differentiation of self, and physical IPV. Correlation analysis in this study indicated that for women only relationship satisfaction and marital conflict were related to differentiation of self, and that romantic jealousy, depression and anxiety were related to physical IPV. For males, all factors in this study were related to differentiation of self except for attitude towards violence for women, and that differentiation of self, romantic jealousy, depression, anxiety and attitude towards violence were related to physical IPV. A greater understanding of how these risk factors 
interact with one another and how they inform pathways to physical IPV perpetration for both genders would be vital to the research on IPV and enhancement of prevention and treatment for physical IPV. Future research should also include additional risk factors, such as alcohol problems, anger, etc.

In terms of practice, awareness of the important role that an individual's level of differentiation of self has on perpetration of physical IPV has major therapeutic implications for programs for batterers in general, and for marriage and family therapists. Stith et al $(2004 ; 2011$; 2012) argued that there is a need for systemic treatment and multiple treatment options due to heterogeneity of physical IPV and the fact that researchers have found that both men and women perpetrate physical IPV. Despite the growing body of research supporting more treatment options that are inclusive of partners (when reconciliation is the goal) and systemic in nature, treatment systems for domestic violence often target the perpetrator alone (Stith et al., 2011). Often the batterers are expected to complete some form of group batterer intervention program (Tolman \& Edleson, 1995) for their domestic abuse and victims may access support services through shelters and related programs. These programs lack the focus on relational dynamics (Stith et al., 2011), and treatment outcome studies have shown minimal effectiveness and high drop-out rates for male (Babcock, Green, and Robie, 2004; Feder \& Wilson, 2005) and female offender programs (Dowd, Leisring, \& Rosenbaum, 2005). Findings from this dissertation may inform efforts to target systemic treatment for individuals presenting with physical IPV and couples who choose to remain together after experiencing physical IPV.

Family therapists working with individuals and couples presenting with physical IPV, when family therapy is not contraindicated, may need to assess for levels of differentiation of self in the relationship and work to enhance levels of differentiation in the treatment process. 
Lack of or low levels of differentiation diminish the capacity of individuals to exercise control over impulses or emotionally-charged situations. Low levels of differentiation lead to fusion of the intellectual and emotional system which causes individuals to be more likely to give in to the emotional pressures of people close to them, thereby causing them to think and act in specified ways. Such high degree of fusion and the overfunctioning of one person over the other in a significant relationship can lead to loss of one's integrity and sense of self, high conflict, or emotional cutoff. Intuitively violence could be imminent. Family therapists are best equipped to intervene to help individuals and partners presenting with such symptoms to work towards higher levels of differentiation which would allow partners individuality and autonomy along with the ability to balance and set appropriate boundaries in the relationship. When we assist individuals and couples presenting with IPV on enhancing levels of differentiation of self we increase the likelihood for them to deal with conflict appropriately, reduce anxiety, emotional reactiveness, and ultimately reduce the chances of re-occurrence of intimate partner violence. This raises another implication for researchers and practitioners in the field of marriage and family therapy: development of evidence-based interventions that target enhancement of level of differentiation for individuals. We do not know whether working on boundaries, communication skills, or self esteem has an effect on level of differentiation of self. Therefore there is a need in our field to develop and test interventions that address differentiation.

Lastly, this research could inform both prevention and treatment efforts with individuals presenting in therapy with dating violence where the focus could be assessment of differentiation of self followed by education and interventions to increase levels of differentiation of self. This study could also inform family therapists and other professionals involved in premarital counseling and other related family life education domains. 


\section{Limitations}

Limitations of this study relate to the nature of the data and the population of focus. First, all reports were self reports. One question that rises is whether data would be different if they were corroborated with the partner's report. Secondly, data were used in the analysis as individual data and not as couple data due to the number of variables in the study and lack of enough couple data for statistical power. Lastly, participants were being screened to be accepted into a program, and some of the data may have been subject to socially or program desirable answers, and/or a pretreatment effect may have had an impact on answers. One of the questions of such an effect in this study for example had to do with the self report on 'attitudes towards violence for women' that did not turn out to be as significant a factor as proposed in this study.

The issue of missing data, particularly as it relates to the outcome measure was somewhat problematic. Because there was no way to insist that respondents answer the questions and it does also appear that there was no probing or repeating of questions to generate better data collection efforts some data were left as missing. In addition, the length of the questionnaire may have caused some respondents to lose interest and to only answer those questions that were less threatening or those that posed little barriers because they were not required to remember events from the past, still others may have chosen to eschew those questions precisely because they did generate unpleasant memories. Whatever the case, the issue of missing data is one that posed a problem for this analysis.

Another limitation of the data came in the form of how certain variables were assessed. For example, there were several interval-ratio level measures that were assessed as categorical data, for example age. Other measures that were categorized include education and income. These structural measures often tend to be very important indicators and could possibly have 
served as a basis for determining other differences within the sample had they been available in their original form. These data are often grouped in the belief that people feel more comfortable answering questions when they are not required to give a direct answer- this conventional wisdom has not been sustained by census surveys which always ask for direct answers and in their raw form on these measures. Whatever rationale is used, categorical and ordinal level data reduce the explanatory power and can limit the type of analysis and results that can be produced.

Lastly, another limitation could be related to the measure used to assess differentiation of self. Though this measure has been used in other previous research, and it captures differentiation as defined by Bowen, one can make the argument that it may not capture aspects of differentiation addressed by Knudson-Martin $(1994,1996)$ in her expanded definition of differentiation from her research with women from collectivist cultural backgrounds. Future research could explore development and use of more in-depth measures for differentiation that can address Knudson-Martin's suggestions.

\section{Conclusion}

While there is substantial research on risk factors for perpetration of IPV, there is scarce research on role of differentiation of self on IPV and the effect of gender on IPV and its effect on the relationship of differentiation of self and perpetration of IPV. Furthermore, there is a need for future research on these factors. Understanding the role of differentiation on IPV, gender differences, and the moderating effect of gender in the relationship between differentiation of self and IPV facilitates a greater understanding of risk factors for IPV, thus informing both research for future direction and practice for identification of opportunities for prevention and treatment. In addition to providing insight on the impact of differentiation of self on IPV and gender effect, this study raised questions about the interactions between known risk factors for 
IPV, an important future direction for research with implications for research and treatment systems for IPV. 


\section{References}

Adams, C. F. (2004). Francis. Familiar Letters of John Adams and His Wife Abigail Adams During the Revolution. New York: Penguin Books. (First published by New York: Hurd and Houghton, 1876).

Ackerman, J. M. (2012). The relevance of relationship satisfaction and continuation to the gender symmetry debate. Journal of Interpersonal Violence, 27, 3579-3600.

Anderson, S. A., \& Sabatelli, R. M. (1992). Differentiation in the family system scale: DIFS. American Journal of Family Therapy, 20, 77-89.

Andrews, J. A., Foster, S. L., Capaldi, D. M., \& Hops, H. (2000). Adolescent and family predictors of physical aggression, communication, and satisfaction in young adult couples: A prospective analysis. Journal of Consulting and Clinical Psychology, 68, 195208.

Archer, J. (2000). Sex differences in aggression between heterosexual partners: A metaanalytic review. Psychological Bulletin, 126, 651-680.

Archer, J. (2002). Sex differences in physically aggressive acts between heterosexual partners: A meta-analytic review. Aggression and Violent Behavior, 7(4), 313-351.

Babcock, J. C., Costa, D. M., \& Green, C. E., (2004). What Situations Induce Intimate Partner Violence? A Reliability and Validity Study of the Proximal Antecedents to Violent Episodes (PAVE) Scale. Journal of Family Psychology, 18(3), 433-442.

Babcock, J. C, Green, C. E., \& Robie, C. (2004). Does batterers' treatment work? A meta-analytic review of domestic violence treatment. Clinical Psychology Review, 23, 1023-1053.

Barnett, O.W., \& Hamberger, L.K. (1992). The assessment of maritally violent men on the California Personality Inventory. Violence and Victims, 7, 15-28. 
Barnett, O. W., Martinez, T. E., \& Bluestein, B. W. (1995). Jealousy and romantic attachment in maritally violent and nonviolent men. Journal of Interpersonal Violence, 10(4):473-486.

Barnett, O. W., Miller-Perrin, C. \& Perrin, R. (2005). Family violence across the life span: An introduction ( $2^{\text {nd }}$ ed.). Thousand Oaks, CA: Sage Press.

Bartle-Haring, S. (1997). The relationship among parent-adolescent differentiation, sex role orientation and identity development in late adolescence and early adulthood. Journal of Adolescence, 20, 553-565.

Bartle, S. E., \& Rosen, K. H. (1994). Individuation and relationship violence. The American Journal of Family Therapy, 22, 222-236.

Bartle-Haring, S., Rosen, K., \& Stith, S. (2002). Emotional Reactivity and psychological distress. Journal of Adolescent Research, 17, 568-585.

Bartle-Haring, S., \& Probst, D. (2004). A test of Bowen theory: Emotional reactivity and psychological distress in a clinical sample. The American Journal of Family Therapy, 32, 419-435.

Bartle, S.E. \& Sabatelli, R. M. (1995). The Behavioral and Emotional Reactivity Index: Preliminary evidence for construct validity from three studies. Family Relations, 44, $267-$ 277.

Beere, C. A., King, D. W., Beere, D. B., \& King, L. A. (1984). The sex-role egalitarianism scale: A measure of attitudes toward equality between the sexes. Sex Roles, 10(7/8), 563-576.

Black, M.C., Basile, K.C., Breiding, M.J., Smith, S.G., Walters, M.L., Merrick, M.T., Chen, J., Stevens, M.R. The National Intimate Partner and Sexual Violence Survey (NISVS): 2010 Summary Report. Atlanta, GA: National Center for Injury Prevention and Control, Centers for Disease Control and Prevention; 2011. 
Bloch, R. H. (2007). The American Revolution, wife beating, and the emergent value of privacy. Early American Studies, 5(2), 223-251.

Bradbury, T. N., \& Lawrence, E. (1999). Physical aggression and the longitudinal course of newlywed marriage. In X. B. Arriaga \& S. Oskamp (Eds.), Violence in intimate relationships (pp. 181-202). Thousand Oaks, CA: Sage.

Bray, J. H., Williamson, D. S., \& Malone, P. E. (1984). Personal authority in the family system: Development of a questionnaire to measure personal authority in intergenerational family processes. Journal of Marital and Family Therapy, 10(2), 167-178.

Breiding, M. J., Black, M. C., \& Ryan, G. W. (2008). Chronic disease and health risk behaviors associated with intimate partner violence - 18 U.S. states/territories, 2005. Annals of Epidemiology, 18(7), 538-544.

Bonomi, A. E., Anderson, M. L., Rivara, F. P., \& Thompson, R. S. (2009). Health care utilization and costs associated with physical and nonphysical-only intimate partner violence. Health Services Research, 44, 1052-1067.

Bowen, M. (1966). The use of family theory in clinical practice. Comprehensive Psychiatry, 7(5), $345-374$.

Bowen, M. (1978). Family therapy in clinical practice. New York: Jason Aaronson.

Boyle, D.J., \& Vivian, D. (1996). Generalized versus spouse-specific anger/hostility and men's violence against intimates. Violence and Victims, 11(4), 293-317.

Brown, D. S., Finkelstein, E. A., \& Mercy, J. A. (2008). Methods for estimating medical expenditures attributable to intimate partner violence. Journal of Interpersonal Violence, $23,1747-1766$. 
Cano, A., \& Vivian, D. (2003). Are life stressors associated with marital violence? Journal of Family Psychology, 17, 302-314.

Chung, H., \& Gale, J. (2006). Comparing self-differentiation and psychological well-being between Korean and European American students. Contemporary Family Therapy, 28, $367-381$.

Coker, A. L., Davis, K. E., Arias, I., Desai, S., Sanderson, M., Brandt, H. M., \& Smith, P. H. (2002). Physical and mental health effects of intimate partner violence for men and women. American Journal of Preventive Medicine, 23, 260-268.

Cronbach, I. (1951). Coefficient alpha and the internal structure of tests. Psychometrika, 16, 297334.

Derogatis, L. R. \& Melisaratos, N. (1983). The Brief Symptom Inventory: An introductory report. Psychological Medicine, 13, 3, 595-605.

Diop-Sidibe, N., Campbell, J. C., \& Becker, S. (2005). Domestic violence against women in Egypt wife: beating and health outcomes. Social Science \& Medicine, 62, 1260-1277.

Dowd, L., Leisring, P. A., \& Rosenbaum, A. (2005). Partner aggressive women: Characteristics and treatment attrition. Violence and Victims, 20, 219-233.

Dutton, D. G. (1994). Patriarchy and wife assault: The ecological fallacy. Violence and Victims, $9(2), 125-140$.

Dutton, D. G. (1995). The domestic assault of women: Psychological and criminal justice perspectives. Vancouver, BC: UBC Press.

Dutton, D.G., van Ginkel, C., \& Landolt, M.A. (1996). Jealousy, intimate abusiveness, and intrusiveness. Journal of Family Violence, 11(4), 411-423 
Elieson, M. V., \& Rubin, L. J. (2001). Differentiation of self and major depressive disorders: A test of Bowen theory among clinical, traditional, and Internet groups. Family Therapy, The Journal of California Graduate School of Family Psychology, 28(3), 125-142.

Feder, L., \& Wilson, D. (2005). A meta-analytic review of court-mandated batterer intervention programs: Can courts affect abusers' behavior? Journal of Experimental Criminology, 1, $239-262$.

Fenton, B., \& Rathus, J. H. (2010). Men's self-reported descriptions and precipitants of domestic violence perpetration as reported in intake evaluations. Journal of Family Violence, 25,149158.

Friedman, E.H. (1991). Bowen theory and therapy. In A.S. Gurman \& D.P. Kniskern (Eds.) Handbook of family therapy: VII. (pp. 134-170). New York: Brunner Mazel.

Gelles, R. J., \& Harrop, J. W. (1989). Violence, battering, and psychological distress among women. Journal of Interpersonal Violence, 4, 400-420.

Gelles, R. J., \& Straus, M. A. (1988). Intimate violence. New York: Simon and Schuster.

George, D., \& Mallery, P. (2010). SPSS for windows step by step: A simple study guide and reference 17.0 update, $10^{\text {th }}$ Edition. Boston, MA: Allyn and Bacon.

Glickauf-Hughes, C., Foster, M.A., \& Jurkovic, G. (1998). Treating fused couples: What Brownian therapist can learn from their object relations colleagues. Journal of Couples Therapy, 7, 21-32.

Goldner, V., Penn, P., Sheinberg, M.,\&Walker, G. (1990). Love and violence: Gender paradoxes in volatile attachments. Family Process, 29, 343-364.

Gottman, J. M. (1999). The marriage clinic: A scientifically based marital therapy. New York: W. W. Norton. 
Gough, H. G. (1968). California psychological inventory: An interpreter's syllabus. Palo Alto, CA: Consulting Psychologists Press, Inc.

Grandin, E., Lupri, E., Brinkerhoff, M., (1998). Couple Violence and Psychological Distress. Canadian Journal of Public Health, 89(1), 43-47.

Haj-Yahia, M. M. (2003). Beliefs about wife beating among Arab men from Israel: the influence of their patriarchal ideology. Journal of Family Violence, 18,4, 193-206.

Haj-Yahia, M. M. (2000). Beliefs of Jordanian women about wife beating. Psychology of Women Quarterly, 26, 282-291.

Hamburger, L. K., \& Hastings, J. E. (1991). Personality correlates of men who batter andnonviolent men: Some continuities and discontinuities. Journal of Family Violence, $6(2), 131-147$.

Hannawa, A., Spitzberg, B., Wiering, L., Teranishi, C. (2006). "If I Can't Have You, No One Can": Development of a Relational Entitlement and Proprietariness Scale (REPS). Violence and Victims, 21(5), 539-60.

Hastings, J. E., \& Hamburger, L.K. (1988). Personality correlates spouse abusers: A controlled comparison. Violence and Victims, 3, 31-48.

Henning K., \& Conner-Smith, J. (2011). Why doesn't he leave? Relationship continuity and satisfaction among male domestic violence offenders. Journal of Interpersonal Violence, 26(7), 1366-1387.

Hotaling, G. T., \& Sugarman, D. B. (1990). A risk marker analysis of assaulted wives. Journal of Family Violence, 5, 1-13.

Johnson, M. P. (1995). Patriarchal terrorism and common couple violence: two forms of violence against women. Journal of Marriage and the Family, 57, 283-294. 
Johnson, M. P. (2005). Domestic violence: It's not about gender-or is it? Journal of Marriage and Family, 67(5), 1126-1130.

Johnson, M. P. (2006). Conflict and control: Gender symmetry and asymmetry in domestic violence. Violence Against Women, 12(11), 1003-1018.

Johnson, P., \& Buboltz Jr, W. C. (2000). Differentiation of self and psychological reactance. Contemporary Family Therapy: An International Journal, 22(1), 91-102.

Johnson, M. P., \& Ferraro, K. J. (2000). Research on domestic violence in the 1990s: Making distinctions. Journal of Marriage and the Family, 62(4), 948-963.

Jordan, C. E. (2004). Intimate partner violence and the justice system: An examination of the interface. Journal of Interpersonal Violence, 19, 1412-1434.

Kelly, J. B., \& Johnson, M. P. (2008). Differentiation among types of intimate partner violence: research update and implications for interventions. Family Court Review, 46(3), 476-499.

Kerr, M. E. (1984). Theoretical base for differentiation of self in one's family of origin. Clinical Supervisor, 2, 3-36.

Kerr, M. E. (1981). Family systems theory and therapy. In A. S. Gurman \& D. P. Kniskern (Eds.), Handbook of family therapy. New York: Brunner/Mazel.

Kerr, M.E., \& Bowen, M. (1988). Family evaluation. New York: W.W. Norton \& Co.

Khawaja, M. (2004). Domestic violence in refugee camps in Jordan. International Journal of Gynecology \& Obstetrics, 86(1), 67-69.

Khawaja, M., Linos, N., \& El-Roueiheb, Z. (2008). Attitudes of men and women towards wife beating: findings from Palestinian refugee camps in Jordan. Journal of Family Violence, 23, 211-218. 
Kim-Appel, D., Appel, J., Newman, I., \& Parr, P. (2007). Testing the effectiveness of Bowen's concept of differentiation in predicting psychological distress in individuals age 62 years or older. The Family Journal: Counseling and Therapy for Couples and Families, 15(3), 224233.

Knauth, D. G., \& Skowron, E. A. (2004). Psychometric evaluation of the differentiation of self inventory for adolescents. Nursing Research, 53(3), 163-171.

Knauth, D., Skowron, E., \& Escobar, M. (2006). Effect of differentiation of self on adolescent risk behavior. Nursing Research, 55(5), 336-45.

Knudson-Martin, C. (1994).The female voice: Application of Bowen's family systems theory. Journal of Marital and Family Therapy, 20, 35-46.

Knudson-Martin, C. (1996). Differentiation and self-development in the relationship context. The Family Journal: Counseling and Therapy for Couples and Families, 4, 188-198.

Knudson-Martin, C. (2002). Expanding Bowen's legacy to family therapy: a response to Horne and Hicks. Journal of Marital and Family Therapy, 28, 115-118.

Koepsell, J.K., Kernic, M.A., \& Holt, V.L. (2006). Factors that influence battered women to leave their abusive relationships. Violence and Victims, 21, 131-147.

Kurst-Swanger, K., \& Petcosky, J. L. (2003). Violence in the Home: Multidisciplinary Perspectives. New York: Oxford University Press.

Kurz, D. (1989). Social science perspectives on wife abuse: Current debates and future directions. Gender and Society, 3(4), 489-505.

Lal, A., \& Bartle-Haring, S. (2011). Relationship among differentiation of self, relationship satisfaction, partner support, and depression in patients with chronic lung disease and their partners. Journal of Marital and Family Therapy, 37(2), 168-181. 
Lawrence, E., \& Bradbury, T. N. (2001). Physical aggression and marital dysfunction: a longitudinal analysis. Journal of Family Psychology, 15, 135-154.

Madsen, C. A, Stith, S., Thomsen, C., McCollum, E. (2012). Violent Couples Seeking Therapy: Bilateral and Unilateral Violence. Partner Abuse, 3(1), 43-58.

Maiuro, R.D., Cahn, T.S., Vitaliano, P.P., Wagner, B.C., \& Zegree, J.B. (1988). Anger, hostility, and depression in domestically violent versus generally assaultive men and nonviolent control subjects. Journal of Consulting and Clinical Psychology, 56, 17-23.

Margolin, G., John, R. S., \& Foo, L. (1998). Interactive and unique risk factors for husbands' emotional and physical abuse of their wives. Journal of Family Violence, 13, 315-345.

Max, W., Rice, D.P., Finkelstein, E., Bardwell, R.A., Leadbetter, S. (2004). The economic toll of intimate partner violence against women in the United States. Violence and Victims, 19,3, $259-272$

Murdock, N. L., \& Gore, Jr., P. A. (2004). Stress, coping, and differentiation of self: a test of Bowen theory. Contemporary Family Therapy 26(3), 319-335.

Murray, C. E. (2006). Controversy, constraints, and context: Understanding family violence through family systems theory. The Family Journal: Counseling and Therapy for Couples and Families, 14(3), 234-239.

National Association of Crime Victim Compensation Boards. 2002. Compensation at record highs. Victim Compensation Quarterly, 3.

Pan, H. S., Neidig, P. H., \& O’Leary, D. K. (1994). Predicting mild and severe husband to wife physical aggression. Journal of Consulting and Clinical Psychology, 62 (5), 975-981. 
Panuzio, J., \& DiLillo, D. (2010). Physical, psychological, and sexual intimate partner aggression among newlywed couples: Longitudinal prediction of marital satisfaction. Journal of Family Violence, 25. 689-699.

Puente, S., \& Cohen, D. (2003). Jealousy and the meaning (or nonmeaning) of violence. Personality and Social Psychology Bulletin, 29, 449-460.

Richards, E. R. (1989). Self reports of differentiation of self and marital compatibility as related to family functioning in the third and forth stages of the family life cycle. Scholarly Inquiry for Nursing Practice: An International Journal, 3, 163-175.

Rosen, K. H., Bartle-Haring, S., \& Stith, S. M. (2001). Using Bowen theory to enhance understanding of the intergenerational transmission of dating violence. Journal of Family Issues, 22, 124-143.

Rothman, E. F., \& Corso, P. S. (2008). Propensity for intimate partner abuse and workplace productivity. Violence against Women, 14, 1054-1064.

Schumm, W. R., Nichols, C. W., Schectman, K. L., \& Grigsby, C. C. (1983). Characteristics of responses to the Kansas Marital Satisfaction Scale by a sample of 84 married mothers. Psychological Reports, 53(2), 567-572.

Saunders, D.G. (1988). "Wife Abuse, Husband Abuse, or Mutual Combat? A Feminist Perspective on the Empirical Findings". In Bograd M.L., and Yllö K. Feminist perspectives on wife abuse (pp. 90-113). Thousand Oaks: Sage Publications.

Saunders, D. G., Lynch, A. B., Grayson, M., \& Linz, D. (1987). The inventory of beliefs about wife beating: The construction and initial validation of a measure of beliefs and attitudes. Violence and Victims, 2(1), 39-57.

Schnarch, D. (1997) Passionate Marriage. New York: Norton. 
Schubert, E. E., Protinsky, H. O., \& Viers, D. (2002). Levels of differentiation and marital egalitarianism in men who batter. Journal of Family Theory, 14, 1-19.

Schumacher, J. A., \& Leonard, K. E. (2005). Husbands' and wives' marital adjustment, verbal aggression, and physical aggression as longitudinal predictors of physical aggression in early marriage. Journal of Consulting and Clinical Psychology, 73, 28-37.

Shortt, J.Wu., Capaldi, D.M., Kim, H.K., and Laurent, H.K. (2010). The effects of intimate partner violence on relationship satisfaction over time for young at-risk couples: The moderating role of observed negative and positive affect. Partner Abuse, 1(2), 131-151.

Shuerger, J. M., \& Reigle, N. (1988). Personality and biographic data that characterize men who abuse their wives. Journal of Clinical Psychology, 44, 75-81.

Skowron, E. A. (2000). The role of differentiation of self in marital adjustment. Journal of Counseling Psychology, 47, 229-237.

Skowron, E. A., \& Friedlander, M. L. (1998). The Differentiation of Self Inventory: Development and initial validation. Journal of Counseling Psychology, 45(3), 235-246.

Stith, S. M. (2006). Prevention of intimate partner violence. Volume 13, Issues 3-4 of Journal of Aggression, Maltreatment and Trauma Series. New York: Haworth Press.

Stith, S. M., Green, N. M., Smith, D. B., \& Ward, D. B. (2008). Marital satisfaction and marital discord as risk markers for intimate partner violence: A meta-analytic review. Journal of Family Violence, 23(3), 149-160.

Stith, S. M., \& McCollum, E. E. (2009). Couples treatment for physical and psychological aggression. In D. K. O'Leary \& E. M. Woodin (Eds.), Understanding Psychological and Physical Aggression in Couples: Existing Evidence and Clinical Implications. Washington, DC: American Psychological Association. 
Stith, S. M., McCollum, E. E., Rosen, K. H. (2011). Couples therapy for domestic violence: finding safe solutions. Washington DC: American Psychological Association.

Stith, S. M., McCollum, E. E., Amanor-Boadu, Y., Smith, D. (2012). Systemic perspectives on intimate partner violence treatment. Journal of Marital and Family Therapy 38, 1, 220240.

Stith, S. M., McCollum, E. E., Rosen, K. H., Locke, L., \& Goldberg, P. M. (2005). Domestic violence focused couples treatment. In J. Lebow (Ed.), Handbook of Clinical Family Therapy. New York: John Wiley.

Stith, S., \& Straus, M. (1995). Understanding partner violence: Prevalence, causes, consequences and solutions. Minneapolis: NCFR.

Stith, S. M., Rosen, K. H., McCollum, E. E., \& Thomsen, C. J. (2004a). Treating intimate partner violence within intact couple relationships: Outcomes of multi-couple vs. individual couple therapy. Journal of Marital \& Family Therapy, 30, 305-318.

Stith, S. M., Smith, D. B., Penn, C. E., Ward, D. B., \& Tritt, D. (2004b). Intimate partner physical abuse perpetration and victimization risk factors: A meta-analytic review. Aggression \& Violent Behavior, 10, 65-98.

Stith, S. M., Rosen, K. H., Middleton, K. A., Busch, A. L., Lundenberg, K., \& Carlton, R. P. (2000). The intergenerational transmission of spouse abuse: A meta-analysis. Journal of Marriage and the Family, 62, 640-654.

Straus, M. A. (1979). Measuring intrafamily conflict and violence: The Conflict Tactics Scales. Journal of Marriage and the Family, 41, 75-88. 
Straus, M. A. (1980). Wife beating; how common and why? In M. A. Straus \& G. T. Hotaling (Eds.), The social causes of husband-wife violence (pp. 23-36). Minneapolis: University of Minneapolis Press.

Straus, M. A., Gelles, R. J., \& Steinmetz, S. (1980). Behind closed doors: Violence in the American family. Doubleday, NY: Anchor Press.

Straus, M. A., Hamby, S. L., Buncy-McCoy, S.. \& Sugarman, D. B. (1996). The revised Conflict Tactics Scales (CTS2): Development and preliminary psychometric data . Journal of family issues, 17(3), 283-316.

Sugarman, D. B., \& Frankel, S. L. (1996). Patriarchal ideology and wife assault: A meta-analytic review. Journal of Family Violence, 11, 13-40.

Sugarman, D. B., \& Hotaling, G. T. (1989). Dating violence: Prevalence, context, and risk markers. In A. A. Pirog-Good \& J. E. Stets (Eds.), Violence in dating relationships: Emerging social issues (pp. 3-31). New York: Praeger.

Sutherland, C. A., Bybee, D. I., Sullivan, C M. (1998). The long-term effects of battering on women's health. Women's Health 4, 41-70.

Tjaden, P., and N. Thoennes. (2000). Full Report of the Prevalence, Incidence, and Consequences of Violence Against Women: Findings From the National Violence Against Women Survey. Research Report. Washington, DC, and Atlanta, GA: U.S. Department of Justice, National Institute of Justice, and U.S. Department of Health and Human Services, Centers for Disease Control and Prevention, November 2000, NCJ 183781.

Tolman, R. M., \& Edleson, J. L. (1995). Interventions for men who batter: A review of research. In S. Stith \& M. Straus (Eds.), Understanding partner violence: Prevalence, causes, consequences and solutions, (pp. 262-272). Minneapolis: NCFR. 
Vivian, D., \& Malone, J. (1997). Relationship factors and depressive symptomatology associated with mild and severe husband-to-wife physical aggression. Violence and Victims, 12, 3-18.

Walker, L. E. A. (1996). Assessment of abusive spousal relationships. In F. Kaslow (Ed.), Handbook of relational diagnosis and dysfunctional family patterns. New York: Wiley.

Walker, L. E. A. (1989). Psychology and violence against women. American Psychologist, 44, 695-702.

White, G. L. (1981). Some correlates of romantic jealousy. Journal of Personality, 49, 129-147.

Wilson, M., \& Daly, M. (2001). The evolutionary psychology of couple conflict in registered versus de facto marital unions. In A. Booth, A. C. Crouler, \& M. Clements (Eds.), Couples in conflict (pp. 3-26). Mahwah, NJ: Erlbaum.

Wilson, M., \& Daly, M. (1998). Lethal and nonlethal violence against wives and the evolutionary psychology of male sexual proprietariness. In R.E. Dobash \& R.P Dobash (Eds.), Rethinking violence against women (pp. 199-230). Thousand Oaks, CA: Sage.

Yllo, K. A. (1993). Through a feminist lens: Gender, power, and violence. In R. J. Gelles \& D. R. Loseke (Eds.). Current controversies on family violence. Newbury Park, CA: Sage.

Yllo, K. A. \& Straus, M. A. (1990). Patriarchy and violence against wives: The impact of structural and normative factors. In M. A. Straus \& R. J. Gelles, Physical violence in American families. New Brunswick, NJ: Transaction. 